\title{
Enabling Advanced Reactors for the Market Meeting Summary Report
}

Justin L Coleman, Lori A Braase, Darcie M Martinson

September 2018

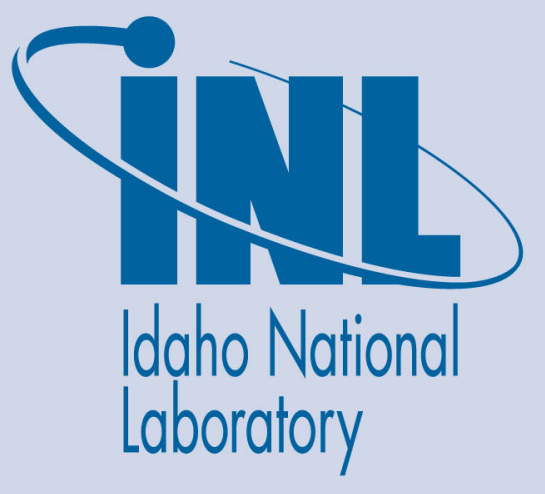

The INL is a U.S. Department of Energy National Laboratory operated by Battelle Energy Alliance 


\title{
Enabling Advanced Reactors for the Market Meeting Summary Report
}

\author{
Justin L Coleman, Lori A Braase, Darcie M Martinson
}

September 2018

Idaho National Laboratory Idaho Falls, Idaho 83415

http://www.inl.gov

Prepared for the

U.S. Department of Energy

Under DOE Idaho Operations Office

Contract DE-AC07-05ID14517 


\section{Enabling Advanced Reactors for the Market Symposium Summary Report}

George Washington University • March 8-9, 2018

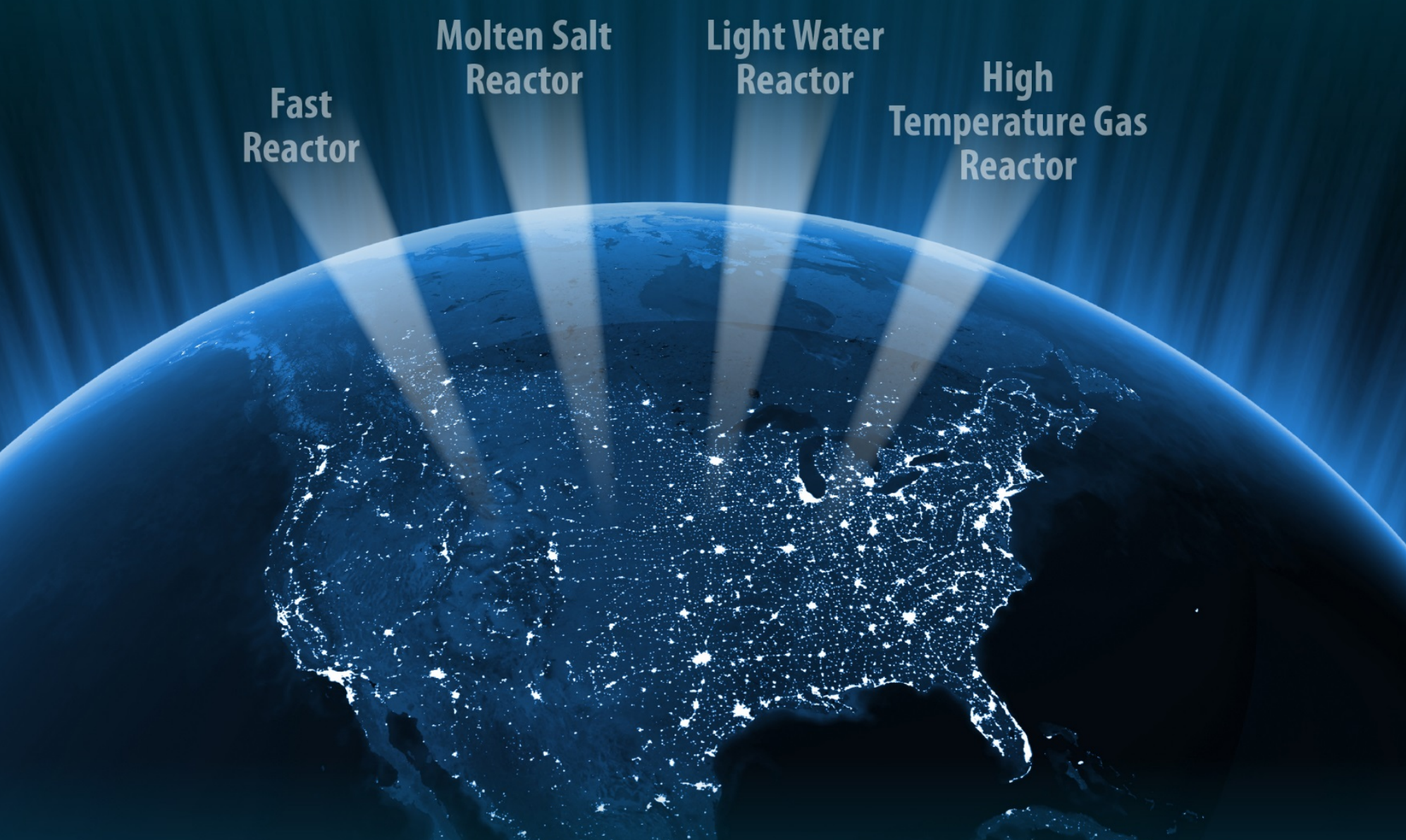

Exploring market opportunities and challenges for advanced reactors

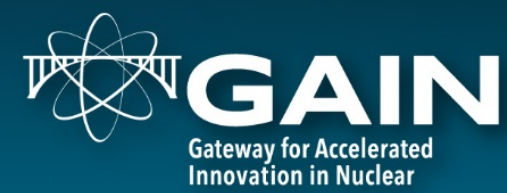

Gateway for Accelerated
Innovation in Nuclear

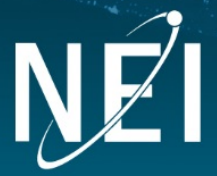

NUCLEAR ENERGY INSTITUTE

gain.inl.gov

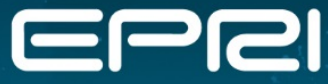

ELECTRIC POWER RESEARCH INSTITUTE 
Prepared by

Justin Coleman, Symposium Integrator

Katie Biegel, Symposium Transcriptionist

Darcie Martinson, Symposium Facilitator

Lori Braase, GAIN Coordinator

Lisa Aldrich, Symposium Technical Editor

Teresa Krynicki, Symposium Coordinator

Prepared under DOE Idaho Operations Office Contract DE-AC07-05ID14517.

Disclaimer

This information was prepared as an account of work sponsored by an agency of the U.S. Government. Neither the U.S. Government nor any agency thereof, nor any of their employees, makes any warranty, expressed or implied, or assumes any legal liability or responsibility for the accuracy, completeness, or usefulness, of any information, apparatus, product, or process disclosed, or represents that its use would not infringe privately owned rights. References herein to any specific commercial product, process, or service by trade name, trade mark, manufacturer, or otherwise, does not necessarily constitute or imply its endorsement, recommendation, or favoring by the U.S.

Government or any agency thereof. The views and opinions of authors expressed herein do not necessarily state or reflect those of the U.S. Government or any agency thereof. 


\section{Acknowledgements}

Enabling Advanced Reactors for the Market Symposium was a great success due to the generous support of the symposium partners.

Thanks to George Washington University (GWU), Professor Ekundayo Shittu, and his students for hosting the symposium in an ideal downtown Washington D.C. location on the GWU campus at the Lehman Auditorium in the Science and Engineering Hall. Professor Shittu and his students were instrumental in the event planning and logistics execution to ensure the symposium ran smoothly. In addition to providing the facility and support, GWU also donated lunches each day.

A big thank you to Katie Biegel, University of Wisconsin - Madison, who volunteered to be the Symposium Transcriptionist. This report would not have been possible without the detailed transcriptions taken by Katie during the symposium. Her meticulous notes provided the basis for the body of content in the summary report.

Thanks to NEI and EPRI in organizing the symposium, from involvement in planning each session, to providing input on the approach, and inviting speakers and participants. NEI and EPRI generously sponsored the evening reception and poster session, which allowed the opportunity for the participants to further engage and network. 


\section{Contents}

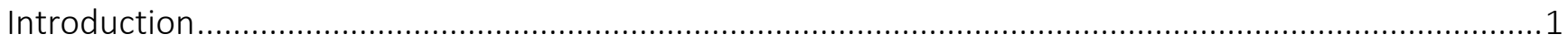

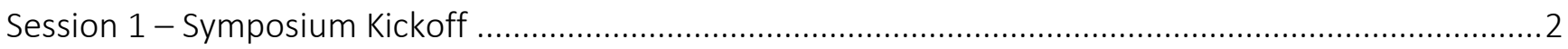

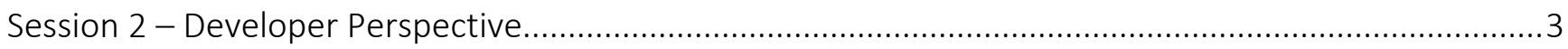

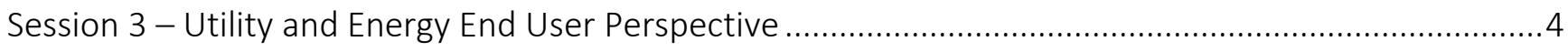

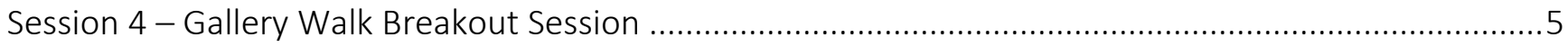

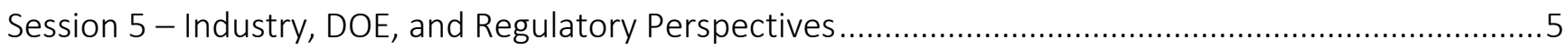

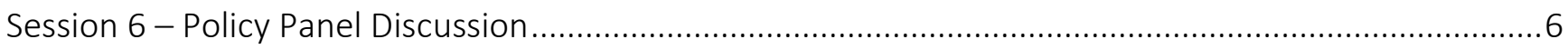

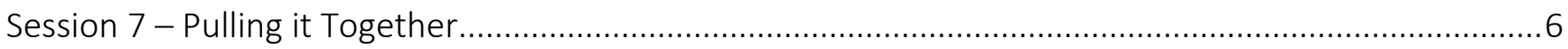

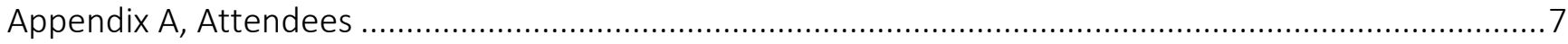

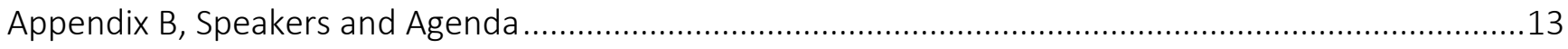

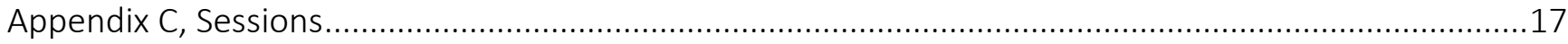

Session 2: Developer Perspective Panel Discussion ............................................................ 18

Session 3: Utility and Energy End User Perspective Panel Discussion............................................21

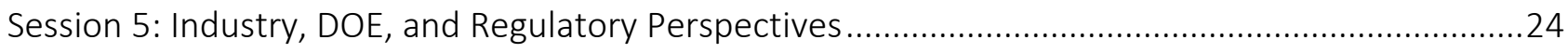

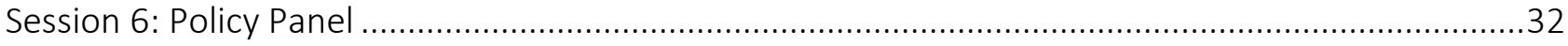

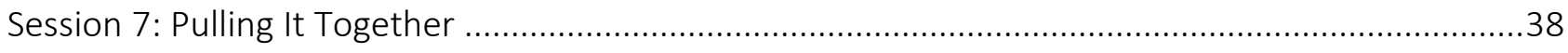

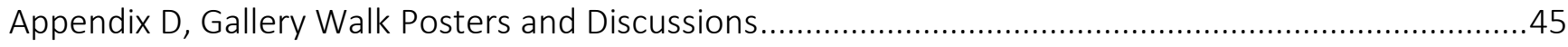




\section{Acronyms}

\begin{tabular}{|c|c|}
\hline DOE & U.S. Department of Energy \\
\hline DOE-NE & Department of Energy-Nuclear Energy \\
\hline EIA & Energy Information Administration \\
\hline EPRI & Electric Power Research Institute \\
\hline ERCOT & Electric Reliability Council of Texas \\
\hline ESBWR & Economic Simplified Boiling Water Reactor \\
\hline FERC & Federal Energy Regulatory Commission \\
\hline FOAK & first-of-a-kind \\
\hline GAIN & Gateway for Accelerated Innovation in Nuclear \\
\hline HALEU & high-assay low-enriched uranium \\
\hline INL & Idaho National Laboratory \\
\hline ISO & Independent System Operators \\
\hline LWR & light water reactor \\
\hline MIT & Massachusetts Institute of Technology \\
\hline NEI & Nuclear Energy Institute \\
\hline NEICA & Nuclear Energy Innovation Capabilities Act \\
\hline NRC & Nuclear Regulatory Commission \\
\hline OPG & Ontario Power Generation \\
\hline PPP & private-public partnership \\
\hline$R \& D$ & research and development \\
\hline RTO & Regional Transmission Organization \\
\hline RPS & renewable portfolio standard \\
\hline SMR & small modular reactor \\
\hline Summer & Virgil C. Summer Nuclear Generating Station \\
\hline TVA & Tennessee Valley Authority \\
\hline U.S. & United States \\
\hline UK & United Kingdom \\
\hline
\end{tabular}




\section{Introduction}

Being prepared for the future means anticipating and adjusting to the ever-changing factors that shape our society. A reliable and resilient energy infrastructure is at the heart of our quality of life and a crucial factor for broad economic competitiveness and employment. Leading us into this future are companies, consumers, and organizations that supply and use energy in novel and purposeful ways.

Advanced nuclear reactors are being developed to meet these future energy needs, including new markets, uses, and applications. Developers, energy producers, industrial users, the government, and other organizations each stand to gain from the success of advanced reactors with the assurance of sustainable and secure energy. However, there are several gaps and hurdles to overcome before realizing this future.

To address the topic of the future energy market and the role nuclear energy plays in providing a reliable energy source in that future market, the U.S. Department of Energy's (DOE's) Gateway for Accelerated Innovation in Nuclear (GAIN) Initiative, the Nuclear Energy Institute (NEI), and the Electric Power Research Institute (EPRI) hosted the "Enabling Advanced Reactors for the Market Symposium," on March 8-9, 2018, at George Washington University. This symposium brought together approximately 120 technology developers, energy users, government representatives, industry, national laboratories, universities and others (see Appendix A for attendee list) to engage in a dialogue about the future energy market and the role of advanced nuclear technologies.
Objectives of the symposium were to:

- Identify opportunities and gaps associated with the economic deployment of advanced reactors and associated technologies

- Enable connection between technology developers and customers

- Provide an energy market context and explore technical deployment opportunities

- Understand the "voice of the customer"

- Understand the federal government's role in advanced reactor policy, regulation, and research and development $(R \& D)$ investment

- Capture the necessary steps to enable advanced reactors for the market.

Appendix B provides the two-day meeting agenda. This meeting summary report follows the agenda by session. Key dialogue boxes share important conversations generated during the sessions.

\footnotetext{
"If you really care about this environment...then you need to be a supporter of this amazingly clean, resilient, safe, reliable source of energy."

Secretary Rick Perry voiced by Deputy Secretary Dan Brouillette, U.S. Department of Energy
}

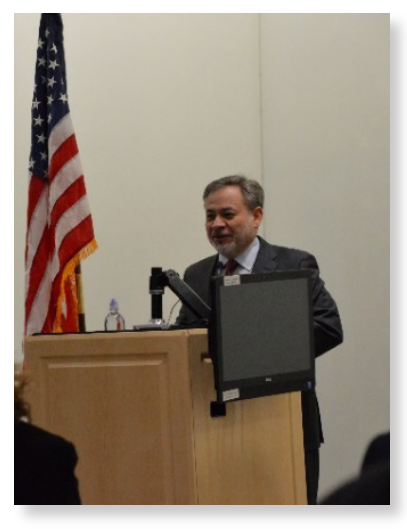




\section{Session 1 - Symposium Kickoff}

Symposium integrator, Justin Coleman (Idaho National Laboratory [INL]), welcomed participants and briefly discussed the nuclear potential and headwinds facing nuclear endeavors today. Host, David Dolling (George Washington University), also welcomed the participants.

Mark Peters, INL Director, provided opening remarks about the importance of preserving the current nuclear fleet. He stressed strengthening the health of the civil nuclear sector and taking a broader perspective to move forward. Moving forward includes development of advanced reactors and involvement from all (DOE, national laboratories, industry, and universities).

David Petti and John Parsons (Massachusetts Institute of Technology [MIT]) provided a preview of results for a soon to be released MIT study. They provided perspective on the importance of advanced reactors to the market and provided reasons for why nuclear reactors are not currently cost competitive. David discussed the costs of new nuclear and establishing a value proposition for advanced systems. John explored the nuclear need topic from an economics perspective. He concluded that decarbonization makes nuclear competitive with other electricity sources under current market conditions.

Concluding Session 1, Rita Baranwal, GAIN Director, explained how industry and investors can access DOE national laboratories capabilities and expertise through GAIN.

The opening session prefaced many questions asked by the nuclear community today, including:

- Where are we? Where are we going? How will we get there?

\section{The ECONOMICS conversation}

The bottom line...end users are driven by economics.

"Utilities only care about cheap electrons."

"Cost is the only thing that a utility executive is being evaluated on."

"Without economic value, there is no decision."

"We in this community have spent a lot of time talking to each other about how great nuclear is, but we're beyond that--the practical issue is a race to the bottom on price in the power markets."

HOWEVER, there are values to advanced reactors that are beyond financial considerations - we should not walk away from the broader economic conversation.

- How can the government help to deploy new nuclear technologies?

- What stifles innovation?

- Where is the cost of new nuclear?

- What is the value of nuclear power?

- Can advanced reactors be licensed and how long will it take to deploy them?

- What role might GAIN play in the commercialization/construction phase outside of research and development? 
Following the kickoff session, the two following sessions were arranged in panel style with a moderator to introduce the panelists and panelist presentations.

\section{Session 2 - Developer Perspective}

Session 2 provided an opportunity for technology developers to identify what they see as future markets for their technologies and how their technology fits into that market. The panel included Ron Faibish, Richard Meyer, Jon Ball, Marcia Burkey, Robin Rickman, and Harlan Bowers. Each panelist provided a presentation summarizing answers to the following questions:

- What is a brief description of your technology?

- What is the specific use case and how does it fit into your targeted market?

- Who is the customer?

- What is missing (e.g., infrastructure)?

- What incentives and policies are needed? Export control?

- What is the readiness level of the technology?

- What is the targeted market entry date and what plans are in place to meet that date?

Following the presentations, the moderator, Ashley Finan (Nuclear Innovation Alliance [NIA]), posed a set of questions from the audience and the panelists answered and discussed. Conversations from Session 2 are provided in Appendix C.

\section{The KNOWLEDGE conversation}

Utilities would like to incorporate advanced reactors into their strategy but don't know how or where to start.

"I feel like I'm on an island and I don't know how to incorporate advanced reactors into our future strategies."

Utilities need assistance or guidance to determine how advanced reactors fit into their strategic plans.

\section{The POLICY conversation}

Federal policy is not necessarily the right answer - the federal government could set the goals and states could structure policies and incentives, driving nuclear forward.

"It's really hard to explain what the government's role is in this space. It's easier to define what the government's role is NOT."

"It's important to get a few policies that put you on the right path."

"If we don't preserve the nuclear fleet, the rest of the conversation doesn't matter." 


\section{Session 3 - Utility and Energy End User Perspective}

Session 3 provided an opportunity for the "customer" (both utilities and energy end users) to talk about the future of their electricity and energy needs. To begin the discussion, John Bistline (EPRI) presented an overview of the recently published Exploring the Role of Advanced Nuclear in Future Energy Markets: Economic Drivers, Barriers, and Impacts in the United States, EPRI Technical Report \#3002011803.

The utilities and end users discussed the role of advanced reactors in their future portfolio (if any) and identified gaps associated with market energy of advanced reactors. The panel included Frederick Moore, Marilyn Kray, Chris Deir, Laura Olson, Brandon Waites, and Dan Stout. Each panelist provided a summary presentation answering the following questions:

- What is your key application?

- What are your requirements? What do you need?

- Do you have any concerns about energy needs being met by nuclear energy?

- What are your reliability, economic, variability and use profile requirements?

- What is your contracting perspective (e.g., if purchasing under power purchase agreement, what are your terms)?

- What incentives do you need to drive nuclear? What incentives are needed to move to a new use case?

- Does your company have internal guidance or policy stating any resources used for that energy supply be clean, non-emitting energy?

\section{The ENERGY SECURITY}

\section{conversation}

Energy security is important, but overshadowed by economics.

"Nuclear has elements of national security, which is not true for other generation sources."

"We should embrace national security implications of civilian nuclear power."

"Thanks in large part to innovations at our national labs and universities, we are on the verge of achieving energy independence and on the road to achieving energy dominance...we are on the road to energy security. A key part of this picture are the 99 commercial nuclear reactors in 30 states across America. Nuclear energy is a key component of our nation's energy portfolio."

The moderator, Dan Lipman (NEI), then posed a set of questions from the audience and the panelists answered and discussed. Conversations from Session 3 are provided in Appendix C. 


\section{Session 4 - Gallery Walk Breakout Session}

A "gallery walk" breakout session was held to promote active engagement by all symposium participants and provide the opportunity to share ideas in a smaller group setting, allowing more people to provide input during a large event. Participants reviewed eight posters of electricity market regions (provided in Appendix D) and selected five of most interest, knowledge, or passion.

Participants gathered at each of their selected regions to review regional information and write responses to questions listed on the corresponding flipcharts. Before leaving each region, the participants were asked to place checkmarks by the listed ideas where they strongly agreed. Data collected from the poster review is presented in with each poster in Appendix D.

\section{Session 5 - Industry, DOE, and Regulatory Perspectives}

INL's director, Mark Peters, moderated this session where the federal perspective was shared on the topic of advanced reactors and nuclear industry. DOE's Deputy Secretary, Dan Brouillette, provided a research, development, and policy discussion. NRC chairman, Kristine Svinicki, provided a regulatory perspective. NEI president and Chief Executive Officer, Maria Korsnick, provided an industry perspective. Conversations from Session 5 are provided in Appendix C.
"Three of our highest priorities at the Department of Energy are reviving and revitalizing nuclear power, accelerating nuclear innovation, and advancing nuclear technology commercialization."

Dan Brouillette Deputy Secretary U.S. Department of Energy

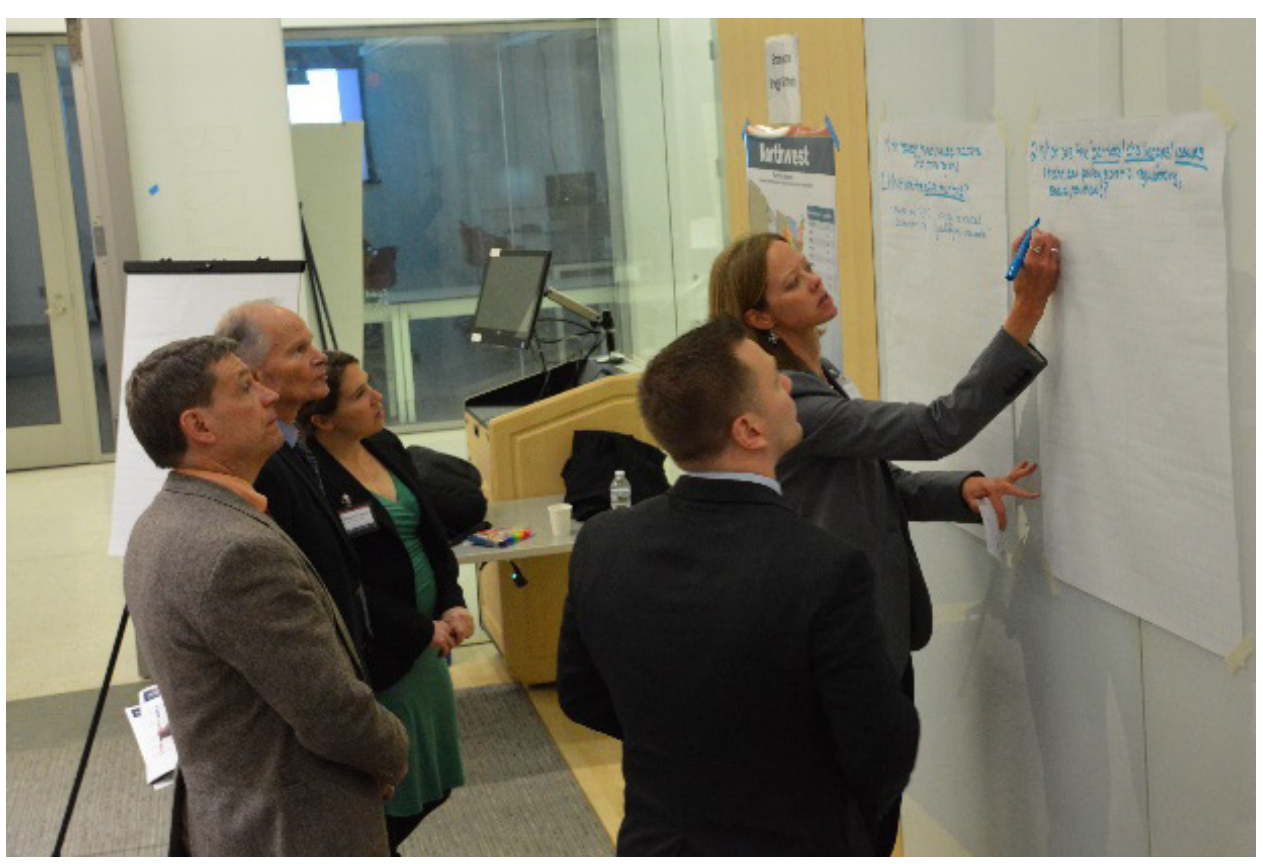

Gallery Walk Station 


\section{Session 6 - Policy Panel Discussion}

John Kotek, NEI vice president for policy development and public affairs, moderated a policy panel discussion. The panel discussed how policy and legislation could be moved through our political infrastructure to remove barriers and reduce gaps for advanced reactor market entry. Each panel participant introduced themselves and discussed their role in energy policy. The panel included Kristy Hartman, Ben Reinke, Adam Rosenburg, and Matt Crozat. John facilitated a general policy discussion and accepted questions from the audience. Conversations from Session 6 are provided in Appendix C.

\section{Session 7 - Pulling it Together}

Session 7 commenced with the honorable Mark Menezes, Under Secretary of Energy, providing a DOE closing message along with his perspective on the energy markets based on his background at Berkshire Hathaway Energy.

Rita Baranwal and Justin Coleman then concluded the symposium by leading an open discussion with participants summarizing challenges, gaps, barriers, and path forward. Conversations from Session 7 are provided in Appendix C.

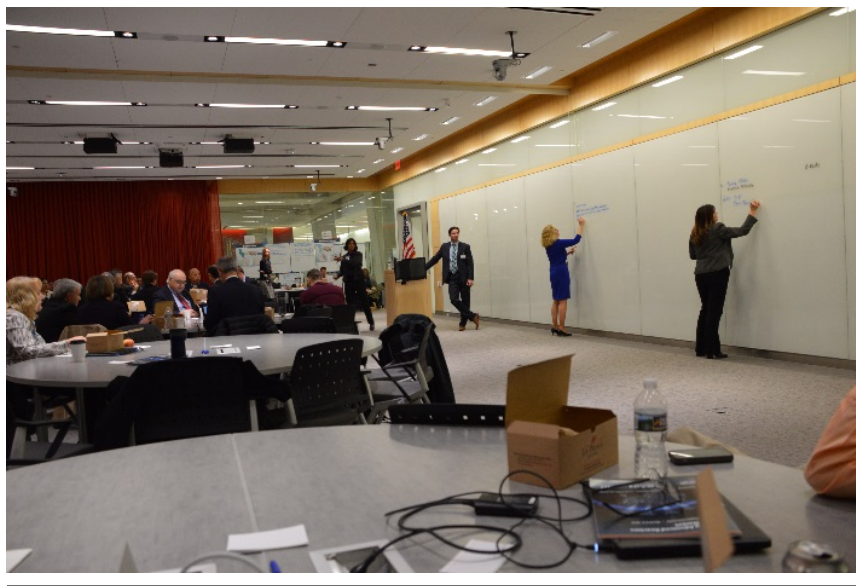

Symposium Integrator, Justin Coleman

A key takeaway is that GAIN must engage stakeholders to identify opportunities to be cost competitive in the energy market and to identify the research, development and deployment needed to close the technology and economic gaps.

To this end, the team will take action to:

- Engage utility and end users to understand plans for future electricity/energy needs.

- Develop and execute an economics initiative plan.

\section{Nuclear energy is a vital component of the President's strategy and vital to the nation's energy portfolio.}


Appendix A, Attendees

7 March 8-9, 2018 | Enabling Advanced Reactors for the Market 


\section{Attendees}

\section{Affiliation}

Advanced Reactor Concepts

Advanced Reactor Concepts

Alpha Tech Research Corp

ARC Nuclear, LLC

AREVA Inc.

Argonne National Laboratory

Argonne National Laboratory

Argonne National Laboratory

ARPA-E

Boron Specialties

Brookhaven National Laboratory

Brookhaven National Laboratory

Brookhaven National Laboratory

Canadian Nuclear Laboratories

Clean Air Task Force

Defense Nuclear Facilities Safety Board

Department of Energy

Department of Energy

Department of Energy

Department of Energy

Department of Energy

Department of Energy - ID

Department of Energy - NE

Department of Energy - NE

Department of Energy - NE

Department of Energy - NE

Department of Energy - Office of Energy Policy \& Systems Analysis

Duke Energy

\section{Name}

Ali Irfan

\section{Donald Wolf}

Staci Wheeler Fullmer

Bob Braun

Farshid Shahrokhi

Hussein Khalil

Jordi Roglans-Ribas

Temitope Taiwo

Rachel Slaybaugh

Beth Bosley

Lynne Ecker

Paul Friley

William Horak

Metin Yetisir

Brett Rampal

Michael Dunlevy

Dan Brouillette

David Solan

Ed McGinnis

Mark Menezes

Sal Golub

Jihad Aljayoushi

Alice Caponiti

Brian Robinson

Michelle Scott

Tom Miller

Kelly Lefler

Adam Reichenbach 


\section{Affiliation}

Duke Energy

Duke Energy

Electric Power Research Institute

Electric Power Research Institute

Electric Power Research Institute

Elysium Industries

Elysium Industries

Elysium Industries

Elysium Industries

Executive Director Emeritus, NGNP Industry Alliance

Exelon Corp

Exelon Generation

GE Hitachi Nuclear Energy

GE Hitachi Nuclear Energy

General Atomics

General Fusion

Generation Atomic

George Washington University

George Washington University

George Washington University

George Washington University

George Washington University

George Washington University

George Washington University

George Washington University

George Washington University

George Washington University

George Washington University

George Washington University

George Washington University

\section{Name}

David Julius

Trevor B. Turner

Andrew Sowder

Barbara Tyran

John Bistline

Carl Perez

Edward Pheil

Gilbert Brown

Youssef Ballout

Frederick Moore

Ugi Otgonbaator

Marilyn Kray

Jon Ball

Pat Looney

Ron Faibish

Matt Miles

Eric Meyer

Alex Beehler

Andrew Magie

Christopher Odufela

Ekundayo Shittu

Joe Cascio

Julian Mowatt

Kayla Tarr

Kiersten Washle

Nana Owusu

Philippe Bardet

Rachel Gray

Yoon Sil Choi

Lindsay Krall 


\section{Affiliation}

Grecheck Consulting, LLC

House Committee on Science, Space, and Technology

Idaho National Laboratory

Idaho National Laboratory

Idaho National Laboratory

Idaho National Laboratory

Idaho National Laboratory

Idaho National Laboratory

Idaho National Laboratory

Idaho National Laboratory

Idaho National Laboratory

Idaho National Laboratory

Idaho National Laboratory

Idaho National Laboratory

Idaho National Laboratory

Idaho National Laboratory

Idaho National Laboratory

Idaho National Laboratory

Kairos Power, LLC

Kairos Power, LLC

Los Alamos National Laboratory

MIT Sloan School of Management

Muons, Inc.

National Conference of State Legislatures

NGNP Industry Alliance

Nuclear Energy Institute

Nuclear Energy Institute

Nuclear Energy Institute

Nuclear Energy Institute

Nuclear Energy Institute

\section{Name}

Eugene S. Grecheck

Adam Rosenberg

Craig Primer

Darcie Martinson

David Petti

Hans Gougar

John Wagner

Jon Carmack

Joseph Campbell

Justin Coleman

Lori Braase

Mark Peters

Pattrick Calderoni

Phil Sharpe

Rita Baranwal

Sarah Chilton

Shannon Bragg-Sitton

Teresa Krynicki

Peter Hastings

Richard Meyer

Chris Stanek

John Parsons

Rolland Paul Johnson

Kristy Hartman

Mark Haynes

Christopher Charles

Dan Lipman

Eric Williams

Everett Redmond

Harsh Desai 


\section{Affiliation}

Nuclear Energy Institute

Nuclear Energy Institute

Nuclear Energy Institute

Nuclear Energy Institute

Nuclear Energy Institute

Nuclear Energy Institute

Nuclear Innovation Alliance

Nuclear Regulatory Commission

Oak Ridge National Laboratory

Oak Ridge National Laboratory

Office of Science and Technology Policy

Ontario Power Generation

Pacific Northwest National Laboratory

Potomac

Purdue University/Generation Atomic

Salt River Project

Senate Committee

Southern Nuclear Development, LLC

TAFrazier LLC

Tennessee Valley Authority

TerraPower

Terrestrial Energy USA

Terrestrial Energy USA

Third Way

Titans of Nuclear

Transatomic Power Corporation

U.S. House of Representatives, Committee on Energy \& Commerce

U.S. Senate Committee on Energy and Natural Resources

University at Buffalo

University of Wisconsin Madison

\section{Name}

John Kotek

Kati Austgen

Marc Nichol

Maria Korsnick

Matthew Crozat

Sean Finnerty

Ashley Finan

Kristine L. Svinicki

Ken Tobin

Andrew Worrall

Mike Goff

Christopher Deir

Stephen D. Unwin

Laura Hermann

Robert Kile

Laura Olson

John Starkey

Brandon Wiley Waites

Timothy A. Frazier

Daniel Stout

Marcia Burkey

Daniel Carleton

Robin Rickman

Suzanne Baker

Bret Kugelmass

Timothy Crook

Andy Zach

Benjamin Reinke

Andrew Whittaker

Katie Biegel 


\begin{tabular}{ll} 
Affiliation & Name \\
University of Wisconsin/Third Way & Todd Allen \\
U.S. Nuclear Infrastructure Council & Caleb Ward \\
U.S. Nuclear Infrastructure Council & David Blee \\
Westinghouse & Alex Harkness \\
X Energy, LLC & Harlan Bowers \\
X-Energy, LLC & Carol Lane \\
Yellowstone Energy & Sam Shaner \\
\hline
\end{tabular}


Appendix B, Speakers and Agenda 


\section{Speakers}

Session 1 - Symposium Kickoff

David Dolling

Mark Peters

John Parsons

David Petti

Rita Baranwal

Session 2 - Developer Perspective

Jon Ball

Executive Vice President

Ron Faibish

Richard Meyer

Marcia Burkey

Robin Rickman

Harlan Bowers

Chief Financial Officer

VP Business Development

President
Dean, School of Engineering \& Applied Science

Laboratory Director

Senior Lecturer

Executive Director

GAIN Director

VP Engineering Operations \& Product Development

Session 3 - Utility and Energy End User Perspective

John Bistline

Senior Technical Leader

Marilyn Kray

Vice President

Chris Deir

Senior Business Manager

Laura Olson

Manager

Brandon Waites

New Projects Manager

Dan Stout

Senior Manager

Frederick Moore

Global Director for Mfg., Technology, \& Energy

Session 5 - Industry, DOE and Regulatory Perspectives

Dan Brouillette Deputy Secretary of Energy

Maria Korsnick President and CEO

Kristine Svinicki Chairman

Session 6 - Policy Discussion

Adam Rosenberg Staff Director, Energy Subcommittee

Kristy Hartman Energy Program Manager

Matt Crozat

Senior Director of Policy Development

Ben Reinke

Professional Staff Member

Session 7 - Pulling it Together

Mark Menezes Under Secretary of Energy

Symposium Moderators

Justin Coleman

Symposium Integrator

Mark Peters

Dan Lipman

John Kotek

Ashley Finan

Laboratory Director

VP Suppliers, New Reactors, and Int'I Programs

VP Policy Development \& Public Affairs

Policy Director
George Washington University

Idaho National Laboratory

Massachusetts Institute of Technology

Massachusetts Institute of Technology

Idaho National Laboratory

GE Hitachi

General Atomics

Kairos Power

TerraPower

Terrestrial Energy, USA

X-Energy

Electric Power Research Institute

Exelon

Ontario Power Generation

Salt River Project

Southern Company

Tennessee Valley Authority

Retired-Dow Chemical Co.

\section{U.S. Department of Energy}

Nuclear Energy Institute

U.S. Nuclear Regulatory Commission

U.S. House Committee

Nat'l Conference of State Legislatures

Nuclear Energy Institute

U.S. Senate Committee

U.S. Department of Energy

Idaho National Laboratory

Idaho National Laboratory

Nuclear Energy Institute

Nuclear Energy Institute

Nuclear Innovation Alliance 


\section{Agenda - Thursday, March 8, 2018}

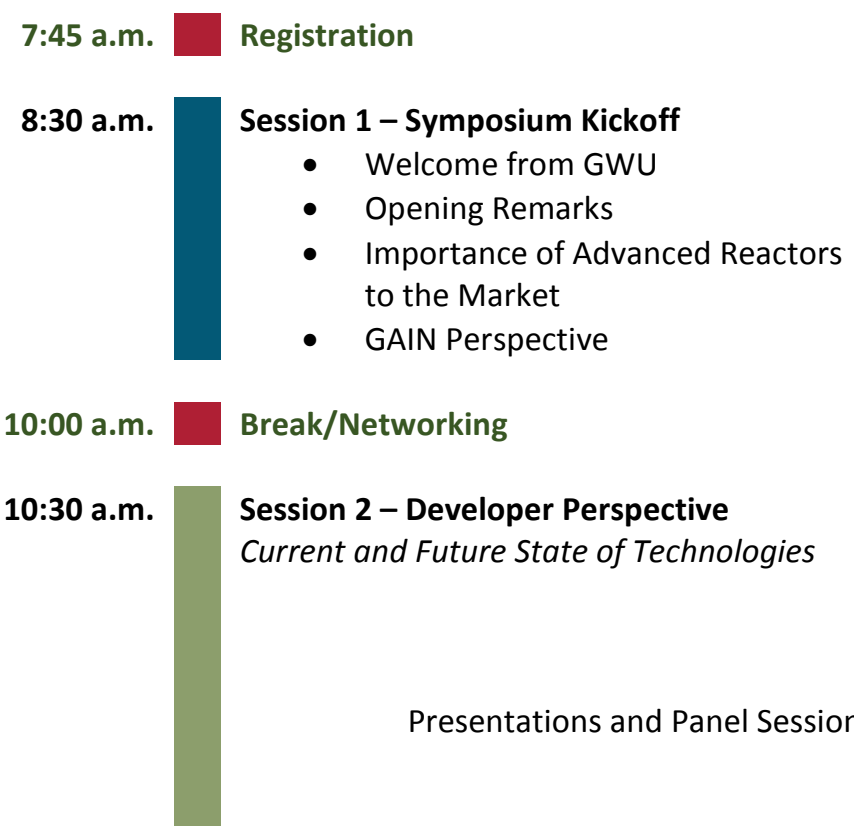

12:30 p.m. Lunch - Hosted by GWU

1:30 p.m. Session 3 - Utility and Energy End User Perspective Current and future state of the market and energy needs. End user perspectives on markets and federal incentives for deployment of advanced reactors.

- Economics of Advanced Reactors

Presentations and Panel Session

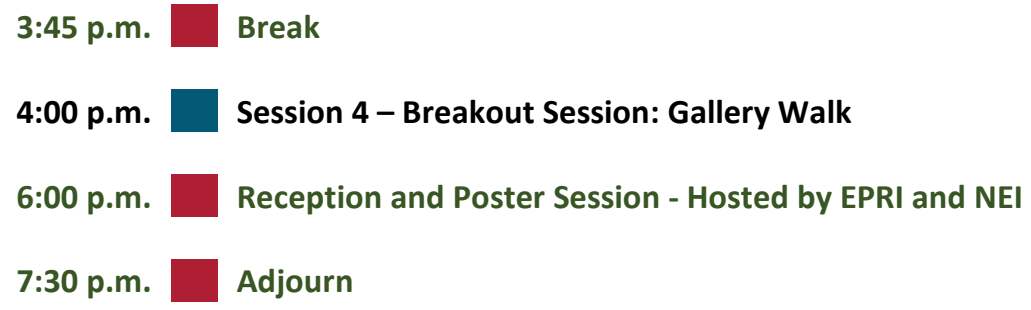

$\begin{array}{ll}\text { Justin Coleman } & \text { INL } \\ \text { David Dolling } & \text { GWU } \\ \text { Mark Peters } & \text { INL } \\ \text { John Parsons } & \text { MIT } \\ \text { David Petti } & \text { MIT } \\ \text { Rita Baranwal } & \text { INL }\end{array}$

Ashley Finan

NIA

Jon Ball

Ron Faibish

Richard Meyer

Marcia Burkey

Robin Rickman

Harlan Bowers

GE Hitachi

General Atomics

Kairos Power

TerraPower

Terrestrial Energy

$X$-Energy

Ekundayo Shittu

GWU

Dan Lipman

NEI

John Bistline

EPRI

Frederick Moore

Dow Chemical Co.

Marilyn Kray

Exelon

Chris Deir

OPG

Laura Olson

Salt River Project

Brandon Waites

Dan Stout

Southern Company

TVA

Darcie Martinson

INL 


\section{Agenda - Friday, March 9, 2018}

7:45 a.m. Registration

8:30 a.m. Session 5 - Industry, DOE, and Regulatory Perspectives

- Regulatory Perspective

- Moderated Discussion

10:00 a.m.

Break/Networking

10:15 a.m.

Session 6 - Policy Panel Discussion

Address Government's Role in Advanced Reactor Policy

- National Conference of State Legislatures

- U.S. Senate Committee on Energy and Natural Resources

- House Committee on Science, Space, and Technology

- Senior Director of Policy Development
Mark Peters

Dan Brouillette

Maria Korsnick

Kristine Svinicki

INL

DOE

NEI

NRC

John Kotek

NEI

Kristy Hartman

Ben Reinke

Adam Rosenberg

Matt Crozat

11:15 a.m.

Break/Networking

11:30 a.m.

Session 7 - Pulling it Together

- DOE Closing Message

- Summarize High Level Symposium Takeaways

Mark Menezes

DOE

Justin Coleman

INL

12:30 p.m.

Lunch - Hosted by GWU / Symposium Wrap-Up

- Participant Feedback

Participants

- Path Forward

- Closing Remarks

Rita Baranwal

Justin Coleman

INL

INL

1:30 p.m.

Adjourn

1:35 p.m.

Information Session 
Appendix C, Sessions

17 March 8-9, 2018 | Enabling Advanced Reactors for the Market 


\section{Session 2: Developer Perspective Panel Discussion}

\section{What is the immediate need for advanced reactor developers?}

- Funding for nuclear fuel. Finding an institutional investor to provide $\$ 800 \mathrm{M}$ is unlikely. However, one suggestion is to look at various funding instruments and strategic partners to build a total package.

- Retiring licensing risk associated with loss-of-coolant accidents. The focus in 2018 is to develop the safety case to have NRC remove that as a consideration.

- Scaling up from small-to-large-scale, control features for load following in control unit, and advanced materials.

- Solidifying customer needs and requirements, including cost and operational requirements for the plant.

- Funding. Developers are using a variety of funding sources, including private capital. Sovereign capital is useful but not needed. There is plenty of private capital available through the capital markets (hundreds of billions of dollars, available for nuclear projects, but capital wants good projects).

- Licensing basis.

- Listening to the voice of the customer.

- Ensuring the advanced nuclear technology supply chain is ready and available.

How much of the Economic Simplified Boiling Water Reactor (ESBWR) licensing basis will be applied to the very small boiling water reactor licensing bases and how much will that reduce the licensing timeframe?

- Approximately $80 \%$ of ESBWR can be taken directly. It is hard to estimate time reduction, but it should be a shorter and less costly certification process.

- The preference is to avoid NRC 10 CFR Part 52 (Licenses, Certifications, and Approvals for Nuclear Power Plants). 10 CFR Part 50 (Domestic Licensing of Production and Utilization Facilities) gets to market much quicker using ESBWR.

- The schedule within an 8-10 year timeframe is aggressive, but 10 is certainly doable.

\section{How important are 123 Agreements for peaceful nuclear cooperation and for which countries?}

- The 123 Agreements are very important. Much of the market is growing outside of the U.S. in Saudi Arabia, India, Canada, United Kingdom (UK), as well as Asian markets.

- The most important 123 Agreement is with China, which "underpins everything we are doing."

- "For significant nuclear exports, the country must have a 123 Agreement for peaceful nuclear cooperation pursuant to Section 123 of the U.S. Atomic Energy Act of 1954, as amended. In order for a country to enter into such an Agreement with the United States, that country must commit itself to adhering to U.S.-mandated nuclear nonproliferation norms. Significant nuclear exports include power reactors, research reactors, source and special nuclear materials (for use as reactor fuel), and four major components of reactors (pressure vessels, fuel charging and discharging 
machines, complete control rod drive units, and primary coolant pumps). A 123 Agreement typically does not commit the United States to any specific exports or other cooperative activities, but rather establishes a framework of conditions and controls to govern subsequent commercial transactions, if any." https://www.export.gov/industries/civil-nuclear/exporting-guide/123agreements.

What is the model TerraPower envisions for deploying nuclear technology in nations with greatest human development index need?

- They are starting in China, which has a talent pool and supply chain for megaprojects, experience with advanced reactors, and an experienced regulator. They need to demonstrate the prototype in China first because of a better support structure.

Would implementation of the MIT report be sufficient for companies to deploy first-of-a-kind (FOAK) in the U.S.?

- Yes, for the most part. It is critical for easing some FOAK burdens.

- Power purchase agreements are especially intriguing.

\section{How are customer interactions driving your products?}

- When the very small boiling water reactor started, a FastWorks program was initiated to engage customers to understand the elements most important to them. Cost-competitiveness was their single largest issue.

- Applying product development techniques, interviewing many different customers, and quantifying needs, found that flexibility is not very important at the individual plant level.

\section{Can you use 10 CFR Part 50 (Domestic Licensing of Production and Utilization Facilities) to have emergency planning zones adjudicated before construction starts?}

- This is a key element to NuScale.

- The reactor park, as suggested by the MIT study, is on the right track. This should allow for larger emergency planning zones that can be reduced over time to accelerate plant deployment

\section{How does your technology address cost competitiveness and financial risk?}

- Many of the advanced reactor technologies address cost competitiveness and financial risk by simplicity and volume, decreasing risk in the construction phase, smaller total cost (being off by $10-20 \%$ has a much smaller impact), and decreasing risk with project implementation.

- Minimize oversight cost and levelized cost of electricity, as well as total initial capital costs. Vogtle and Summer are looking at huge escalation costs. The idea is to start at $\$ 1 \mathrm{~B}$ with ability to grow the plant with modularity over time with electricity sales. This idea needs direct input from a utility.

- The utility/owner wants to minimize financial risk. Accepting high technology risk up-front may lead to lower financial risk in the end with innovation (not necessarily thinking about financial risk initially). When pushing the limits of technology, the goal is to compete with other low-cost options through aggressive technology development. 
- At the stage of design/early innovation, the design process is likely to wildly change the financial analysis. However, the bounds of financial acceptability constrain the design process. Risk can be controlled by knowing the mechanisms of the financial analysis and informing engineering by changing the financial analysis as the design changes.

What are the human resource challenges associated with advanced light water reactors (LWRs) since there is no Navy nuke pipeline?

- Reducing operating costs via automating personnel requirements can release personnel resources (sources of talent) for advanced reactors.

- Advanced technology will require fewer personnel via autonomous systems and licensing for partially autonomous systems will be challenging. Development of advanced controls is vital.

- As an example of one successful option, new hires do rotations in different parts of the business. They are rotated through the majority of design engineering. This creates a backlog of engineers in various departments who also the experience with reactor design.

Policy changes that help nuclear in the U.S. electricity market are "out of our control." Should we not try to pass legislation that would be an advantage to nuclear?

- Yes, the advanced reactor community supports legislation, but they cannot depend on those factors to make them cost-competitive.

What assumptions are made in the Kairos's 2030 timeline regarding availability of high-assay low enriched uranium (HALEU) and government testing/qualification?

- They are actively working on the fuel qualification program.

- The programs support deployment earlier than 2030, which is a drop-dead date.

- Kairos is supportive of programs that can provide Category 2 facilities for fuel development and they are willing to work with others to make those investments.

- The supply chain does not have to be established for the first plant. It can be a phased implementation going into the future.

Kairos has funding through 2020. Have you secured funds for research and science labs after that?

- Kairos is fully funded for research and science labs. They are working with the national labs to identify the technology and processes to enrich Li-7. To reduce the amount of tritium produced by plant, a supply of Li-7 is needed in fluoride salt.

Does TerraPower see different markets for a traveling-wave reactor and molten chloride fast reactor?

- Yes, the molten chloride fast reactor is destined for U.S. markets and may eventually be suitable/interested in both markets. It is a lower-cost, higher-quality high heat reactor.

- The traveling-wave reactor will be ready earlier. More work has been done on this system and it has a stronger background. 


\section{Session 3: Utility and Energy End User Perspective Panel Discussion}

DOE's nuclear lift; Canada seems to be doing it. How is the need and process to get alignment on technology and "pick winners" viewed in Canada? How are alignment and requirements determined?

- U.S. is not picking vendor winners. Picking a "stream"/technology type to potentially meet offgrid/heavy resources/in-grid models. They should not have different models for their three major potential use cases.

- Currently, there are 60-80 vendors with technologies in five technology categories. DOE is looking at developers who have R\&D programs that are realistic and have reasonable timelines, fuel supply, supply chain, and financial backing.

- They are not just grouping by technology type, but also sorting developers into echelons of readiness, and comparing that status to their needs.

- All technologies need to build prototypes, but DOE cannot build them all.

What makes you think the government can pick winners? Did they not pick a winner for the LWR?

- If they do not pick a winner, is it realistic that any technology can be commercialized?

- The reality is some type of scoring mechanism is needed, but nothing will happen if you cannot down select.

- The supply chain will have to be enormous and will end up fragmented.

- Whether it is a specific vendor or a broader technology category/type, focus is needed to winnow down the options.

If the federal government in the U.S. picks winners (technologies), what would that do in terms of utility decision-making (e.g., Southern Company is collaborating with at least two developers)?

- Look at the GAIN Advanced Reactor Directory. It is getting larger, which is a good sign, but also a dilution of potential resource targets.

- Options are needed, but a steady state needs to occur where there are fewer new entrants. Then bucket technologies into families to start converging into concepts.

- Even if all designs had good characteristics, industry does not have the appetite to keep them all alive, and they will eat each other's market share.

- Down selecting would be helpful, but not by the government. Industry should pick with end user input. In other situations, request for proposals would be used to solicit concepts. The government actually takes the action to reduce the options.

- To a degree, cost-sharing percentage is a way of allowing industry to pick, with government supporting (private-public partnership [PPP] approach). The PPP is funded $\mathrm{x} \%$ by industry, and $(100-x) \%$ by government. As share by industry increases, this provides a built-in mechanism whereby industry will only support/sign on to PPPs for technologies they think have a chance of being commercialized. This is a natural mechanism to allow industry to pick via PPP funding. More government share/more technology options at low-dollar early R\&D. It would be better to be closer to $75 \%$ industry near the end. 
- It is hard enough to find one site within Arizona to preserve the option for something between an LWR small modular reactor (SMR) and 2xAP-1000s. They cannot include several advanced reactors demonstration options.

- Choosing a winner helps community engagement and keeps it realistic. This is a philosophical question. "Picking" is going to happen, whether it is purposely directed or not.

- In a free-market society, competition and innovation will create favored and unfavorable technologies. It would be a lot quicker with down selection, but it gets back to philosophy. Down selection will happen, but it depends how far down the road you kick the issue.

- The current structure/framework of federal investment needs a tweak that would allow the natural selection to happen anyway. There should not be a mandated down select filter. Actions should not be taken that will thwart technology development.

If one policy could be implemented to enable deployment of advanced reactors, what would that policy be? Have any of you advocated for a carbon tax?

- Exelon's Government Affairs has presented to different states regarding what it would take to preserve currently operating reactors, namely valuation of its carbon-free nature, which has worked. Could call it a subsidy/cost of carbon. Have worked very hard with NEI at state and federal level to advocate for favorable carbon-pricing/environmental policy reform to acknowledge carbon-free nature of nuclear.

- A pure carbon tax can be like a drug. A carbon-neutral tax would work. A carbon intensity balance, a sort of cap and trade, could work by zip code. This might drive innovation.

- Other than carbon tax, it is unclear how else you would make up such a huge cost difference between nuclear and natural gas. If you want to spur anything in the next decade, I do not know how else that could be accomplished.

- Whether they like it or not, Canada has the carbon tax. Once the Canadian government recognized that nuclear is "clean and green," just like renewables, the federal government engaged, they "started showing up." Everything else is peanuts. A loan guarantee is nothing unless the government is really engaged. Canadian/Ontario government officials go way out of their way to tout Ontario being carbon free, along with nuclear energy's role in that.

- The real question is, "How do we help nuclear make it?" At a higher level, what is important is to develop an overall generation diversity policy that values nuclear explicitly and adds equitable value to each generation source. This would drive natural gas in other energy areas as well. A policy could be proposed that helps nuclear, but it would be better to join forces with advocates for other sources for more combined political power. It is hard and ineffective to just take shots at each other. For example, we must have coal. The U.S. has a very large reserve, and it is a strong part of the economy and likewise for natural gas. The opposition to clean carbon legislation in NY is not anti-nukes, it is NRG/fossil providers feeling threatened, "they are the actual formidable opponents." Not sure how to accomplish this, but we need to get on the same side.

- Policy duration is an issue. How long would this policy need to be in place, having a constant effect, for it to help? The runway/lead time for nuclear is 10 years. The production tax credit was not guaranteed enough to keep SCANA Corp's project going. In addition, we have to live with the reality of 4-year administration change. Betting big asset purchase decisions on potentially temporary policies is hazardous. 


\section{How actively has the developer community engaged with your organization?}

- "I feel very alone." I am one of the only people saying, "we're trying to plan for new nuclear." I do not know what that means, I am a policy person, and it is hard as a nonnuclear entity to get into this arena. Our utility has partial ownership in a nuclear power plant, but that status and experience is not helpful in navigating this process/decision. Our utility does not know what developers are doing, and nobody is stepping up to provide us with resources. We are looking to examples from other utilities but have no action from developers. The Utah Associated Municipal Power Systems and NuScale could be a potential example, but they have a DOE partnership, which is not a model our utility could turn to and is not replicable. I am trying to learn about technologies and processes-looking for help.

- Our company has been very bullish in nuclear and in the advanced reactor community. We want to have optionality - our goal is to have diverse portfolio. There is no need to put all our eggs in one or two baskets. This is not a good way to approach an uncertain future. Our company does have partnerships with developers. We have met with several different developers. They are very receptive to advice and asking questions. Interactions have been very positive.

- The developer community has spent a great deal of time on their concepts and utility interest is rising due to the credibility lent by that work. Utilities will have a bigger role as designs mature and economics adjust.

- Ten years ago, several utilities wanted to build nuclear plants and competed to get in the queue to get stuff made. We now have to adapt to the current paradigm of reluctance. Currently, the reason for no load growth is that energy efficiency is working and rooftop solar/distributed energy sources are available, turning customers into non-customers. There are industrial customers looking to site large production facilities/data centers, asking for commitment to provide large power source. We need to go to Google and Amazon and convince them to want "clean" energy rather than "renewable" energy.

- It is hard to build a reactor when you do not need it. Generally, we understand the technology. The business case is not working.

- How many of you have gone to the utilities like PJM Interconnection (PJM) and explained to them the value of resiliency, and how your reactor can improve it? PJM and others think the markets work just fine the way they are. I applaud vendors who reach out to end users.

- A recommendation was made to establish an advisory council, or a more informal feedback structure. 


\title{
Session 5: Industry, DOE, and Regulatory Perspectives
}

\author{
DOE Perspective, Dan Brouillette, Deputy Secretary of Energy
}

Three of DOE's highest priorities are reviving and revitalizing nuclear power, accelerating nuclear innovation, and advancing nuclear technology commercialization. DOE and the advanced reactor community have an opportunity to work together to achieve those goals.

DOE believes that the nation is on the verge of achieving energy independence, a longtime goal, due in large part to innovations at national labs and universities. In addition, the nation is on the road to achieving energy dominance, which also leads to energy security. Key components are the 99 commercial reactors in 30 states across the U.S.

Nuclear energy is a vital component of the President's strategy, and vital to the nation's energy portfolio. As Secretary Perry has stated, "If you really care about this environment... then you need to be a supporter of this amazingly clean, resilient, safe, reliable source of energy." For America's electrical grid, there is no more reliable fuel than nuclear power.

Despite the advantages of nuclear energy, the nuclear sector is currently confronted with historic challenges including complex market factors, falling alternative generation costs (the market at work) and lower electricity demand. These combined factors make operating some nuclear plants uneconomical.

Faced with these challenges, the nation must pivot and adapt to realize future opportunities, by rethinking, reimagining and reengineering. SMRs and advanced reactors are a clear part of the solution. Smaller capital investment, modularity, greater efficiency and flexibility must be part of the mix. America's private sector understands this opportunity and responds with investment and innovation. More than 50 companies and institutions are working on innovative advanced nuclear designs, and dozens of developers are seeking to deploy these concepts in North America, backed by nearly $\$ 2 \mathrm{~B}$ in private investments.

Development of new advanced nuclear technology is a complicated and expensive process requiring unique facilities and materials that are impractical for the private sector to maintain. That is where DOE can help. DOE has a long history of nuclear power development, much of it accomplished at world-class laboratories, using their unique facilities. These $R \& D$ investments became the foundation for the successful light water reactor industry.

Today, scientists and engineers at the national labs and universities are enabling new and advanced designs that promise to be safer, more environmentally friendly and more economically viable than ever before. Activities are being explored to support the development of a new Advanced Test Reactor by 2026 to accelerate innovations in advanced fuels and materials and reestablish some lost capabilities.

To ensure a lasting nuclear revival in the nation, we are leveraging the national lab system and university research, pushing a resilient supply chain, and promoting a strong nuclear pipeline. GAIN is a great example of this approach by establishing private-public partnerships to leverage technology advancements and to focus federal investments on priority research and capability needs. Building on GAIN, a multi-year funding opportunity announcement has been published to support the development of advanced nuclear technologies.

There is great potential to work together to revive, revitalize and renew the nation's nuclear sector. Developing and advancing technologies will benefit citizens for years to come. This is an opportunity to affect our nation in a truly historic way through the energy, innovation, and ingenuity of those who in attendance at the symposium today. 


\section{Industry Perspective, Maria Korsnick, NEI President and CEO}

It is very fair to say there are challenges. We would like to reflect on the state of the industry, how we see things looking forward. NEI has established a "national nuclear energy strategy" including the following.

\section{Preserving}

There is value of the current fleet to the U.S., but current plants are very much challenged. There have been six premature closures. Even though the licensed life would have allowed continued operation, the plants were closed prematurely. Another eight closures have been announced. This number is likely subject to underreporting. There are other plants/companies under significant stress, but official closure plans have not been announced. This is not a good path for us to be on, and we need to do something. An average windmill gives you 3-4 MW, at a 30\% capacity factor. It would take several windmills to replace closed nuclear plants.

NEI is about having this conversation on the Hill and bringing awareness. Nuclear energy is in a situation where mothballing is not possible. Once you stop operations, even temporarily, you have to draw on decommissioning funds, which starts you down a path that is hard to reverse. Efforts need to be brought to bear now to clarify status of plants at risk.

In Canada, they consider nuclear green, but this is not true in the U.S. People are putting initiatives on ballots (AZ, MN, and CO) to declare that clean energy does NOT include nuclear. This is not "just a ballot initiative." It changes the constitution in those states and sets precedents of definitions exclusive of nuclear. We need really to care about that.

Twenty-five years ago, when "renewable portfolio standard (RPS)" became a term of wide use, renewables seemed insignificant, but this is no longer the case. They are a challenge to nuclear by crowding out under limiting RPS definitions.

Things are happening at the state level--because the states really feel the effects of the plant closures. In anticipation of a potential plant closure in New York, a meeting was held with local officials. The head of the school board was told: "You're the school system. If that plant goes away, there's no one else showing up with that $\$ 20 \mathrm{M}$ check every year." Plants are local infrastructure. Not only for great jobs, but they have become lifeblood of local community.

How can we value nuclear more appropriately in the market for clean air, clean energy and resilience? Policy changes are not happening at federal level, so things are happening at state level instead. Connecticut had established a clean energy market, but the local nuclear provider was not allowed to bid in at all until legislation was changed (not a subsidy, just needed an opportunity to play).

Energy efficiency, low demand and subsidies for other generation types are "almost a perfect storm for nuclear." We have to keep focused to change views in the policy and public sphere. We have data on our side. When talking to environmentalists, they should love us based on the data that supports the importance of nuclear power, but in some cases, it is more passion than facts. Some people in the environmental world have campaigned so long against nuclear it is hard to change their views, but some are coming around. We all need to be sharing the message with anyone we can.

\section{Sustaining}

This is an opportunity for the industry to look at itself and ask, "How do we run things and how can we be more efficient?" Ongoing operational efficiency measures have resulted in $\$ 1.6 \mathrm{~B}$ in savings/year across industry. We are working with NRC to improve risk-informed regulation where lots of efficiency can be gained. 
Ninety percent of plants already have their first license renewal. We are currently seeing first movers for second-license renewals (going to 80 years). Eventually, we will be looking ahead to 100 years - there is nothing magic about 80 . These plants are built and maintained robustly and should not be judged by calendar years. Keep in mind we are currently only building two reactors.

Look at the improvements in the nuclear operational record ( $60 \%$ capacity factor in the $80 \mathrm{~s})$. Now we are in the in the $90 \%$ s for capacity factor. We should be very proud of our operational record.

Regarding power uprates, we have built, without building, over 30 new reactors in the U.S. We have onethird more electricity on the market must by operating what we have better. This is very positive, but we do not have one-third more to give.

\section{Innovating}

New technology is going to come in all makes and models (1-2MW, 300MW, and $1 \mathrm{GW})$. It is important to value having the full suite of options. Think about remote locations like Africa. You cannot plop down a $1,500 \mathrm{MW}$ reactor there. They do not have the transmissions for it.

Value is being placed on portable and small reactors. That is happening and in the pipeline right now. Would like to target a 2020 deployment date, not 2050. There is a line item in FY 2019 request for NRC to support microreactor licensing.

We need new tools in the toolbox.

\section{Thriving}

Innovations are being brought to the U.S. and the global marketplace. We must be aggressive. There is Saudi interest in building reactors, and we are very interested in supporting that.

The U.S. has not played a significant enough role in the worldwide marketplace. We need to create a conversation with the policymakers. We should not stand by idly, watch other countries (China, Russia), and not have a strong U.S. foothold. We bring safety standards, nonproliferation standards, a high capacity factor, and great operations record to the table. 


\section{Regulatory Perspective, Kristine Svinicki, NRC Chairman}

Advanced reactors are in the current view of NRC and not seen as a future thing. They are a "center of gravity" in the nuclear policy dialogue. NRC is developing a vision/strategy document, supported by near, mid and long-term implementation plans (0-5 years, 5-10 years, beyond 10 years). Near-term plans include:

- Acquiring or developing sufficient knowledge and technical competencies to review non-LWRs

- Acquiring or developing sufficient computer codes analytical tools

- Developing guidance for flexible regulatory review process conducted within bounds of existing regulations, phased/staged licensing

- Facilitating industry codes and standards to support non-LWR life cycle

- Identifying and resolving policy issues that impact non-LWRs, and do so in a tech-agnostic way

- Developing/implementing strategy to engage with all impacted communities of interest on all topics, showing up and communicating.

Progress is being made and it is anticipated that NRC could receive advanced reactor license applications in the next 2-4 years. Expressions of interest are needed and then the budget can be structured to accommodate future applications.

NRC recently contracted with Oak Ridge National Laboratory for an advanced reactor training course. Ninety people received the training including not only technical experts, but also lawyers and other nontechnical staff to establish breadth of competence (whole agency is involved). Research staff have also received MOOSE/BISON code training for interoperability with what the labs are doing.

NRC is actively participating in a licensing modernization project (with Southern, cost share from DOE). The focus is to prove principle of technology-inclusive performance-based regulatory guidance. Right now, they are reviewing white papers including selection of licensing basis events, probabilistic risk assessments, and others.

NRC is engaged with DOE. There are good people at DOE including new people who are bringing new energy.

Secretary Perry is very committed to this. It has been mentioned, "I thought there was someone behind the curtain with the power solving our obstacles, but look to your left and look to your right; these are the people who will solve your problems. No one is coming to help you." If we do not do something now, the window might be closing.

I am excited by the rising generation in nuclear. The North American Young Generation in Nuclear is doing valuable work. If we stumble, confident young people in the industry will regroup.

We have an opportunity. We have lots of center of gravity around advanced reactors. It is time to move advanced reactors into physical realm rather than discussion. We do not have the funding. We cannot even fund an infrastructure bill for falling-down bridges. Therefore, everyone has to put forth effort.

In 1990, we would never have expected bipartisan support. In 12 years in the senate, it made no difference. If we agree on the problem and there is opportunity space that allows for both of our solutions, we can both win. 


\section{Industry and Regulatory Panel Discussion}

\section{Regarding the Virgil C. Summer Nuclear Generating Station (Summer), is the project unrecoverable?}

Panelist response

Of the companies that are currently interested in buying SCANA Corp, none of them have expressed interested in restarting Summer. Restarting Summer would be a major financial drag and is not something they are giving as a reason for their interest in the purchase. Currently, there is interest in maintaining uninstalled components ( $\$ 10 \mathrm{M} /$ year to maintain). The important first step is maintenance. I am not optimistic for any near-term restart. However, it would be a fabulous positive example to finish Vogtle under a "great banner of success."

The best thing we could do in the U.S. is to continue to build. Experience atrophy is main reason for difficulties at Vogtle and Summer. South Korea has had continuous build, and they have improved their build schedule by $30 \%$. We need to continue to focus on the "skill of remembering."

Look at difference between the two new reactors at the Vogtle site. The first time a component is installed, it takes 45 hours, but the second time it takes 15 hours so there is learning that occurs from the first to the second. Imagine what you could do with ' $n$ ' experiences. Is there potential to leverage Vogtle experience on eventual future restart at Summer?

\section{We have lots of bipartisan support for nuclear, but how do we get policies in place that are durable and enabling?}

Panelist response

One major challenge is picking a winner. Another challenge is maintaining bipartisan support of making nuclear part of the mix, saying "and you must have nuclear." We must be specific about the benefits of nuclear. "Nuclear is special and unique." It has elements of national security, which is not true for other generation sources.

Policy can support nuclear. Convincing Federal Energy Regulatory Commission (FERC) to give nuclear more credit for positive attributes in the marketplace would be a linchpin for us. If nuclear gets credit for its benefits, it can compete in the market. If my power supply will be appropriately recognized, then there is a reason to build a new nuclear power plant. At the end of the day, we must look ahead and gain recognition for environmental benefits (clean air, carbon free). There is real value being brought to the marketplace by nuclear that's left unvalued.

\section{Panelist response}

Part of me wants to say, "I do not really believe in the value of policy anymore." This administration has policy of supporting nuclear, but in isolation, this does nothing. All the things that manifest below that broad goal are actually important. Lower-level things have a bearing on decision making and getting things accomplished.

Once people (e.g., renewables) are getting subsidies, you have crossed a bridge. "I'm a free-market conservative." If you do not believe nuclear can compete and win on its own merits, you probably did not get a nuclear engineering degree. We need some physical accomplishments for the rising generation to look to, some successes. Vogtle would be something to point to, but there is a whole dialogue about whether or not it can be done. 


\section{Panelist response}

Think about long-term power purchase agreements. They are very beneficial for a technology that needs proof to be able to come online. The Department of Defense may have interest in long-term power purchase agreements for SMR technology. This is a very promising and doable thing and allows the government to play an appropriate role in encouraging technology development.

\section{What do we do about spent fuel? What about closing the fuel cycle?}

\section{Panelist response}

We need to be loud and proud about used fuel but the name is misleading. It is as if we are building a goldmine for our kids and grandkids that they will want to access. There is lots of energy left in there; $95 \%$ of the energy remains after removal from the reactor. "Today's trash is tomorrow's treasure." This resource is labeled in a negative way (e.g., what are we going to do about this problem?).

We are working very hard with those on Capitol Hill to push a bill supporting Yucca Mountain and interim storage and are optimistic that in March 2018 that bill will advance to the floor in the House. This is an important step and we are optimistic for bipartisan House support. There are, of course, still political challenges, but we are hopeful to have an opportunity to see that advance.

The concern around used fuel can be appreciated. However, prior to successful legislation, we should think about changing the dialogue around used fuel and educating the public. As an anecdote from a Canadian conference, a former professor became a nuclear and spent fuel proponent and advocate after educating himself.

In reality, used fuel is in an easy-to-store, easy-to-monitor state, and it is well-characterized. Currently, we have inefficient geographical distribution and decommissioned sites want their land back.

\section{Panelist response}

Recent coordinating discussions were held and we are rebuilding the document repository on the project. The next phase would be continuation of evidentiary hearings.

We have visited many decommissioning sites and stood at Trojan, seeing nothing but green field except for casks. Literally nothing there. There are other sites like that.

We are capable of better than this. Regarding the refuel cycle, ask developers, "If this was the dawn of the atomic age and we had all the computing power of the current day, would you pick LWRs?" The answer is universally no.

It is hard to think of a comparable technology arc. Is there any other technology that has been held back so much from its full potential? The technology is frozen in time. That is not saying that LWRs are not marvels. It is saying that we can do a lot better.

For the rising generation, who are we to tell them "no" if they want to harness the atom in a better, more efficient way, especially if other nations are trying new things? We should be exporting our safety/security culture and using nuclear as a mechanism for foreign policy projection.

If our nation does not have a program, the whole future of the world looks different. There are a lot more negative than positive things about the U.S. being out of the nuclear game. If we are just operating, we are out of the game, even if we operate to 100 years. In the timeframe of a nation, that is a "brief dalliance." 


\section{What is your response to NRC not moving fast enough?}

\section{Panelist response}

I think we are capable of doing that phased process. Why are we letting Canada get ahead of us? Where is your fighting spirit? Canada courting people in the U.S. ignites a spirit of action.

We can do the phased process. We are at the beginning stages. Believing that our system is so agile is actually making it difficult for the developers. Developers seem to want/need a menu of some choices and concrete steps to get through the process. What things make sense to you as a developer? Could do white papers, design review, staged review, etc. The GE's/Westinghouse's of the world did not need it. They had a path through the traditional mechanisms.

It has been a distractor to think we need a lot of legislation. We think the Atomic Energy Act has it pretty well covered.

\section{What are your comments on the dialogue in the industry about "modernization" of regulation?}

\section{Panelist response}

NRC did not seize on the opportunity to influence National Electrical Manufacturers Association standards. Regarding the White House Policy Review, NRC should be in a mode to participate actively, rather than just play defense. If we got an application tomorrow, the framework would be in place, but would appreciate the opportunity to re-orientate.

There is a lot to do on design certification for non-LWR technology to be successful within a reasonable timeframe. Even though I have full confidence we would get through, the challenge is we need more predictability.

The whole community is not Westinghouse/GE. They have venture capitalists /angel investors who demand predictability and scrutability. The challenge is having enough foresight and granularity. There are new technology challenges, which we will have to resolve. We do not think we have it in the bag. There are a lot of moving parts. We need near/mid/long-term goals and a detailed understanding of the challenges.

The current setup is not a slam-dunk. Without some changed paradigms about risk, there is not a clear success path. NRC needs to understand the potential impacts of taking risks versus not taking risks. Imagine your job is signing off that "nothing bad will ever happen." Eventually, your personal risk threshold becomes lower and lower.

There needs to be a consistent organizational push to make sure individuals' risk tolerance and scrutiny stays at an appropriate level. The U.S. fleet keeps performing better and better. Improvements become little tweaks around the edges, and the last risk mitigation bits are most expensive.

Standing still is never an option. Pivot points cause a step change. I would challenge NRC. We do not want to do risky things, but we should challenge ourselves about that level of risk. Nuclear will succeed or fail on the regulatory question.

\section{Panelist response}

The industry jumped quickly to legislative "encouragement." The reality is there is a framework available, but there is a very LWR-centric view. There is now an opportunity to reevaluate that LWR focus. How can developers be given encouragement that their technology can make it through the process?

I am encouraged with where things stand with movement towards risk-informed regulation and culture change. Licensees should be able to take advantage of risk-informed regulation. If you are sitting with an 
NRC staffer and they are not open to the conversation about a current challenge your plant faces and if they prefer a deterministic approach even if you have a good risk-informed model, you are stuck in the deterministic world. One challenge is that institutional forces keep reinforcing existing practices, not pushing the envelope on risk-informed decision making. That culture needs to be changed for advanced reactors.

The NRC Chairman gets it and is pressing the NRC staff for that risk-informed thinking. For example, we have been working on digital instrumentation and controls for over a decade, which is ridiculous. Fossil plants have way more advanced control rooms/systems than nukes. We are holding the industry hostage to innovation.

\section{Panelist response}

Testing of materials is vital.

NRC can talk a good game about an advanced reactor design application readiness, but right now, we are engaging existing plants, and if we do not change our behavior, we will not be able to convince a single member of congress that we will actually handle advanced reactors appropriately. Change starts now.

Accident tolerant fuel is not revolutionary. If that cannot be tolerated by the system, what hope is there for advanced reactors?

\section{Regarding the comment, "less keynotes, more dialogue," who else should be in the room for this discussion?}

Panelist response

Dreamers should be in the room. Engaging with North American Young Generation in Nuclear/students is important. People who think boldly need to be in the room, people who have energy. Coordinators and organizers of people should be in the room as should outreach experts and facilitators. Nontechnical people, people who are inspirational (often not a core competency among technical people) should be here. Third Way efforts are an example, they have Ghanaian representative, mayors, etc. We keep having an insular dialogue and seeing the same people at these types of events.

Regarding those who think boldly, it helps to visit the nuclear plants to see things in context. Somebody saw that plot of land and said, "you know what we need here are 5 nuclear reactors." The boldness of those people is humbling, and some plants are named after those bold people.

\section{Panelist response}

There are rarely different people in the room but do not think small. This road has been hard and long, but do not let it beat you down into incremental thinking. You are the innovators, closest to the technology. The spark needs to come from here, from this group of people. If we do not think boldly/broadly, no one will do it for us. Do not give up, we need to harness that spirit and drive to make good things happen in policy/regulatory space. Remain inspired. 


\title{
Session 6: Policy Panel
}

\author{
Introductions
}

\section{Moderator comments}

- The right policies can create strong market signals. RPS and other measures are creating a policy environment in which wind can thrive, in addition to DOE efforts to bring down technology cost. We can get there with nuclear too, but we have to focus on right policy outcomes.

- Third Way shout out. We need to improve "public license" acceptance and embracing of the technology. As seen in survey research, nuclear is only slightly more popular than coal.

- Important American Nuclear Society initiative (Navigating Nuclear: Energizing Our World ${ }^{\mathrm{TM}}$ ) http://www.ans.org/pi/navigatingnuclear/.

- Must be raising awareness of nuclear energy's beneficial attributes. As we do a better job of telling the nuclear story and building a better public license for nuclear technology, we will open the door for policymakers to create more favorable policies. There have been recent favorable developments (e.g., Nuclear Energy Innovation Capabilities Act [NEICA]).

\section{Panelist 1}

- NEICA summary

- Ranking member Johnson, House Committee on Science/Technology was the co-sponsor. Lead sponsor is from Texas. In the Senate, they passed their version of the standalone bill recently. Senate Energy passed HR 589 and S 2503 in markup. This includes NEICA, but also includes other helpful provisions and authorized tech transfer provisions that are important.

- First authorization of energy innovation hubs. The Consortium for Advanced Simulation of LWRs, a major nuclear hub, will be wrapping up in the next year, but there may be follow-on action.

- They want whole package to move. I encourage the audience to advocate for it on Capitol Hill.

- NEICA includes authorization for a versatile neutron source, important for fast reactors and others, developing fuels and materials. It also authorizes nuclear innovation energy center for testing advanced reactor tech, at a lab location, without requiring a full NRC license and includes appropriate coordination with NRC.

- The budget request for nuclear energy is not good. Currently, there is opposition to movement on demonstration of "anything" that is support for nuclear or carbon capture and sequestration. There is a focus from this administration on "early-stage/basic research" with no definition for what that means. This is a big problem for advanced nuclear. The loan program office is on the chopping block completely and it is unlikely to commercialize anything without it. The office would be entirely eliminated. There was a recent MEITNER (Modeling-Enhanced Innovations Trailblazing Nuclear Energy Reinvigoration) announcement regarding Advanced Research Projects AgencyEnergy and the administration's proposal to eliminate it again. 
- Commenting on the Democrats' support for nuclear, there has been a broad characterization that Democrats are anti-nuclear. There is more renewables support among that party. There is an issue with environmental groups that are opposed, but they do not speak for the Democratic Party. There have been thoughtful conversations with various environmental groups on broadening their pitch for clean energy and including nuclear. Johnson and other caucus members are supportive of a broad portfolio of technologies, including carbon capture and sequestration and nuclear, to address climate issues. We need to continue fostering those relationships.

\section{Panelist 2}

- Murkowski is a strong supporter of the Advanced Research Projects Agency-Energy and a supporter of robust R\&D budgets, but not happy about proposed cuts and marks. This is an opportunity for Secretary Perry to discuss the R\&D budget.

- It is hard to explain what the government's role should be in accelerating your path to market. Nuclear energy and policy are both hard, but that does not mean we cannot make progress. It is easier to define what the government's role is not.

- The government's role in this space is not down selecting. This has been tried in the past and it did not work so well. The pervasive idea that we want a large federal energy policy to "solve all of these problems" may not be the right answer. In reality, members are there to represent people from their districts and changing law to help their people. Problems are geographic and social in nature. Different regions have different resource sets and concerns and one monolithic federal policy is hard.

- A lot of time was spent trying to put a large energy packet together, and it did not work. It has been over 10 years since we last passed a large energy bill. It is not that we do not have an energy policy, but a full comprehensive overhaul would be very difficult and would require a lot of agreement. For example, updates to the American Economic Association, DOE established legislation, Public Utility Regulatory Policies Act, regulatory standards, tax code, and others. These would also have to supersede state law. This is a very technocratic approach so, not sure that is the right answer.

- It will be important to identify policies that help move the ball forward. NEICA was a unanimous consent vote, which is amazing, but it is been in the works for a few years.

- Regarding Senator Flake's proposed bill, DOE's Office of Nuclear Energy should set hard goals that are audacious but attainable. Murkowski's office likes it. The SunShot Initiative was very successful and had a similar structure. It is time that everybody in the audience here should be able to answer, "What are some definitive goals for U.S. policy?"

- Also, have a role in the scientific infrastructure. NEICA jumpstarts versatile neutron source. The U.S. government provides testbed facilities. High assay LEU is needed. Without a fuel stock, a neutron source will not help.

- Work force

- National security is a concern. We should embrace national security implications of civilian nuclear power.

- There is still an underlying connection between reactors and reactor technology/leadership export.

- The conversation is changing on Capitol Hill. If the U.S. does not start leading now, we will not have a seat at the table in the international power reactor community later. University 
programs are very important and we need to be thinking about how this will evolve in the future. Industry and government both need nuclear engineers.

- Government should be an early/first adopter including purchasing power from advanced reactors down the road.

\section{Panelist 3}

- The National Conference of State Legislatures includes representatives from all 50 states and its purpose is to provide unbiased policy research on various issues. Nuclear has come to the forefront in the last few legislative sessions. The focus from state legislatures has been looking at at-risk nuke plants. There is growing interest in the future of nuclear (advanced reactors, SMRs, others) and legislators are looking at what they can do to support those technologies.

- The bills are not regionally specific but are all over the country, by both parties. In 2017, 32 states introduced more than 100 bills on nuclear generation and advanced reactors including looking at different options, interim storage and a permanent repository. In 2016, 19 states introduced 64 bills, which is a big increase from 2016 to 2017.

- It is interesting/unusual that current trends are so clear. Resolutions are being passed to show support for nuclear energy in general. For example:

- AL 2017: bill encouraging ongoing bipartisan efforts supporting efforts for advanced reactors

- AZ 2017: urging EPA to recognize nuclear as clean, urging bipartisan support for nuclear.

The broadest question/trend is how we value nuclear energy and low carbon generation:

- RPS: 29 states and Washington D.C., several states looking at whether nuclear should be considered as part of RPS, or other type of zero-carbon/low-carbon standard that values nuclear

- NM: bill was proposed but not passed to include nuclear in clean-energy goals

- States that include nuclear in RPS: Indiana and Ohio (including advanced reactors)

- More states are introducing bills on carbon tax/cap and trade, especially New England and the west coast. Washington moved further in considering carbon tax; however, it did not pass, but they are continuing the discussion.

Financing and incentives trends:

- States are looking at tax incentive options, for existing or new nuclear plants

- Advance cost recovery is very contentious but it is being discussed

- Integrated resource plans, considering nuclear and long lead times, looking at different options for integrated resource plans that allow more serious/different consideration of nuclear.

Each year we are seeing 5-10 bills from states looking at how to spur development of advanced reactor/SMR technologies:

- 2016 Tennessee bill supporting R\&D for SMR technology

- Washington bills submitted in each session (most have not passed, but there are some pockets of strong support). 


\section{Panelist 4}

- Theory and policy are very different worlds--policy is a world of "second-best." It's important to get a few policies that put you on the right path (e.g., wind tax credit-if the goal was just to create a market for non-emitting tech, it's been a success, and when production tax credits have lapsed investment goes way down, but there are important secondary effects to these types of incentives).

- Thinking through policy design is critical. A proposal this year from Arizona's Public Utility Commission is to have a target of 80\% coming from "clean sources" (including nuclear) by 2050. Palo Verde is the single largest clean energy generator in the U.S. There is also a 50\% RPS proposal out of Arizona, which excludes nuclear. It is hard to see how Palo Verde fits into an $80 \%$ clean energy target if $50 \%$ has to come from renewables.

- There is a practical process to get policies through. Small things matter. In the context of advanced reactors, think about how to move from a concept through commercialization without government backing. We have never seen that succeed in the past.

- There are several developers seeing gaps in the market and they are producing designs to capitalize on important favorable attributes. Technology can meet gaps.

- For example, the ability to load-follow. Why would you pay extra to have the capability not to run? That is crazy. Markets now are not designed to think in these terms, but markets evolve.

- Even now, market organizers are starting to recognize the value of these things.

- Policy creates signals about what is valued. If the attribute you are developing is not valued, there is no reason to deploy it. "Getting through the licensing process" is an important focus. You have to consider incentives. Why should anyone want to build your reactor? Policy helps reflect these values. Accomplishing this takes work. What we have now is not designed to accommodate nonprice values and attributes. 


\section{Policy Panel Discussion}

We have talked about PPPs and power purchase agreements as ways of government participating in the economic case for new build. If you look back far enough, the first wave of nuclear build was through the Power Reactor Demonstration Program, and included a huge range of technologies, a uranium-leasing program, and creative policies to address challenges beyond power purchase agreements. What are other options that deserve attention?

\section{Panelist response}

There is an important role for government in demonstrations of new advanced reactor technologies. It would be great if the private sector could fund FOAK deployments directly, but that is unlikely. PPPs would require a significant amount of federal funds, but right now there's a philosophical issue in the administration and the House (not necessarily just Senate/House Democrats), and general opposition to government being involved with "basic research." It may take a change in the majorities in the chambers. Another issue is the importance and continuance of the loan guarantee program, which may not continue to be an option and would be hard to be replaced.

\section{Panelist response}

The Missouri bill ties deployment of SMRs to having a production/manufacturing facility in the state. The state needs manufacturing jobs and would support construction and operation of a SMR.

\section{Panelist response}

When we talk about need for PPPs, we overlook just how pervasive they are in nuclear development. GAIN supports PPPs. For modeling and simulation, we have the Consortium for Advanced Simulation of LWRs hub. It is not so much a question of whether we are going to have reactors, since we already do. It is more about the timeline and vision of the scale of what they are trying to cover. As you begin to look at deployment costs for FOAK, that is beyond the scale of traditional PPPs. That moves into realm of loan guarantees.

\section{A presenter from Day 1 made a comment that the public contribution to the various technologies be} based on a percent of private contribution. What is your reaction?

\section{Panelist response}

Picking winners is a touchy subject. It almost sounds like an "axiom" that we do not want the government picking winners and losers. They have been fighting the battle in their committee. As an inherent process for R\&D projects, you have to pick winners and losers. Which projects have the most value to the U.S. taxpayer is always a consideration.

Regulatory policy/tax policy should be technology-neutral (e.g., clean energy vs. renewable, carbon tax vs. production tax credits for individual technologies). When we are talking about developing research projects and first demonstrations, we need to be very careful about that language, which has led us down some challenging roads lately. When these demonstration projects are evaluated, the amount the private sector is willing to put in is certainly a major factor in what is selected.

The Energy Policy Act of 2005 requires "skin in the game" from industry for both earlier-stage applied research (20\% cost share) and for later demonstration stage (50\% cost share). The committee can waive this requirement, but in each case, you look at private sector's willingness to invest. Would the industry do this anyway without government involvement? 


\section{Panelist response}

It is important that the market play a strong role in the down selecting and funding processes. Industry involvement is a good thing. We need a broad range of opportunities for engagement with government for lots of technologies at various maturity stages.

Picking technologies for government to fund is very hard. "Valuing the product in the marketplace" is difficult. Price formation in wholesale market is already complicated. There are likely lots of different market segments where nuclear could fit in, but not clear what those are (e.g., electricity vs process heat). How would you value process heat in the marketplace? In addition, the national labs are trying to figure out hybrid energy systems. When structuring PPPs, it is important to think about contextual research (like hybrid-energy system work) to create data to use for market signals/value.

In Alaska, microreactors have been mentioned for remote communities. This is a different market segment and business proposition than for PJM. The cost concepts and values are very different. Remote locations are very dependent on diesel generators and electricity can be up to 10 times more expensive than in "normal" markets. This changes the economic cost/benefit significantly.

Some concepts are likely better suited for process heat, load following, and other nonconventional activities and product streams.

Not all electricity is created equal; resilient/reliable/clean attributes have different values. Down-selecting a particular technology too early is bad because of this diversity of unserved market segments. There are also diverse international opportunities and unserved market needs that provide a caution against overzealous or overly early down selection.

\section{Calls for $100 \%$ renewables are not realistic, but the topic is nuanced. Storage, instantaneous supply/demand balance, and many other factors play a role. How much are these calls for $100 \%$ renewables undermining supportive nuclear policies?}

\section{Panelist response}

I have many reactions to that. The "caricature" of Democratic caucus has been evolving over last 15 years. Reference the Jacobson study, "quasi-activist," and the National Academy of Sciences study.

The call for $100 \%$ renewables does not seem to be a barrier to how the Democratic caucus views the energy technologies that it takes to address climate change. Some Democratic lawmakers do seem to support specific studies (e.g., deploy 100\% renewables).

Why should the U.S. deploy $100 \%$ renewables? Why just automatically choose a certain set of technologies to address this huge challenge if that is not the fastest path to a solution? Why not allow play for a full range of technologies and let the chips fall where they may?

It is possible that renewables will win anyway, given an even playing field (favorable cost trends in wind and solar). Even if we agree on a technology-neutral policy, nuclear might still lose.

\section{Panelist response}

We are trying to create a signal that this is what we value. We must create a connection between what we value and translate that into policy. If you tell me what you are trying to do we can figure out a policy to get there, but we need to figure out how to actually implement that change. Decarbonization is important, market competition will have to encompass a solution. Prescribing how to achieve goals is dangerous and the fear is the goal will be totally cast aside rather than altered, if it proves unfeasible. 


\title{
Session 7: Pulling It Together
}

\author{
DOE Closing Message, Mark Menezes, Under Secretary of Energy
}

There is no better opportunity to fulfill the future than today. No other administration is so dedicated to advancing nuclear power and working to secure a bright future for nuclear energy. The President has called for a complete review of nation's nuclear energy policy to find new ways to revitalize it. People have been nominated who share this vision and are willing to come work in government to advance the agenda. Together, everyone is working aggressively to revive, revitalize and expand nuclear energy capabilities. This includes the production tax credit for advanced reactor facilities.

Nuclear energy is being advanced through targeted early-state investment to ensure a strong domestic industry now and in the future. This approach prioritizes broad industry R\&D focused on resolving earlystage cross-cutting challenges. Strategic focus is being placed on cost-shared approaches pairing labs with industry-identified needs. This approach has been successfully implemented by GAIN. The Department's recent Funding opportunity announcement is in the same model.

Last fall, we called on FERC to consider establishing new pricing rules that factor in reliability and resilience that nuclear power provides. This was the first time in over 30 years we used the authority of the DOE to direct to FERC to fix rules that they had implemented, that are causing premature retirement of fleet. They can fix the rules, but they did not go as far as we had hoped. They did order the Regional Transmission Organizations (RTOs) and Independent System Operators (ISOs) to respond to a series of questions about whether pricing rules in place are causing a resiliency in grid problem. We are awaiting responses to be filed, which will be followed by a 30-day public commenting period.

The benefits of nuclear are many. It accounts for $20 \%$ of the electricity generated in the U.S. and is the nation's largest source of clean power, producing $60 \%$ of the carbon-free electricity. There is no more reliable fuel than nuclear. Nuclear is a reliable, clean, baseload energy that supports health, safety, economy, security and prosperity.

This is our moment of opportunity. After a decade of benign neglect, nuclear energy has the full backing of nation's highest office to use all tools at their disposal. This is a rare occasion, and we should fully embrace it. We have the full commitment of the Secretary to support innovation and follow the science wherever it leads. The commitment to this community is that as you create, innovate and discover, we will support you in every way we can. The human resources in the industry have intellectual and technological acuity, and problem-solving tenacity.

\section{Questions}

\section{How has nuclear risen in prominence so quickly as a focus in this administration?}

New hires have strong backgrounds in energy before being part of DOE. They know about markets, working with public utility commissions, and generation. With pricing at FERC, we saw unprecedented historical closures of otherwise perfectly good nuclear facilities with long remaining useful lives. Markets have self-assembled voluntarily and are not mandated by any law to have the RTO structure or current market rules. Each of these are reviewed by FERC.

In this administration, we are going to push this issue to the forefront of the decision-makers who can determine market rules. This is a stark difference from the prior administration. During the past several administrations, new technologies have been put forth by developers/industry, but NRC has not acted in a 
way that helps bring them to market quickly. This administration has pledged to try to change those processes.

\section{How do you evaluate global competitiveness in advanced reactors as a driver of U.S. leadership in nuclear technology?}

A global view is necessary. DOE is a member of the National Security Council and has eyes on things that other departments do not see. International demand for nuclear power is continually increasing and other nations want nuclear power and they are moving forward with it. They know the benefits, for example, not having to rely on imports of oil and natural gas.

In the past, other nations came to the U.S. We developed nuclear energy first, had the superior intellectual capacity and expertise, and had the ways and means. Now it is different, the world has new powerhouses that have risen, they have developed technology and abilities, and other countries are talking to them. They do not even have to talk to the U.S. (sometimes they only do not to offend us). These other countries make choices not to use our technology, manufacturing, or operations experience and procedures.

We can decide whether we are going to try to lead the world, or step back and cede it to other countries that may not share our values/best interests. This is seen in very real terms. There is a greater concern about what goes on at FERC for national security reasons beyond market rules. What is important for the future of this country vis-a-vis our relationship with other nations on nuclear technology? We must figure out a way forward.

There is a growing interest in advanced reactors, and we have a workforce that currently supports LWRs. How does DOE plan to support development of capable workforce for advanced reactors?

DOE has programs in place (e.g., GAIN). Even more critical is to ask, "are we getting our young bright students to go into nuclear engineering today?" We have nuclear physicists attracted to labs, and that is fine. Where are the nuclear engineers? How can you excite the young when they are making decisions today? GAIN and centers of excellence at universities can help. Workforce development is very, very important.

We also have our own "house to clean up." To others, it appears that the U.S. is not very good about building nuclear facilities. Neither Summer or Vogtle are beacons of success, with many problems. We got away from building facilities in the U.S., and lost considerable talent and supply chain strength, among other things. We always assumed we are America. We can always do it when we put our mind to it. Then, we experienced the problem moving forward with assumptions without supporting a new workforce and supply chain. This is a "moral imperative, not a choice."

Our workforce is a national treasure that we need to develop and maintain. Otherwise, it will be "at our peril that we let it go." 
High Level Symposium Takeaways and Discussion of Next Steps

Rita Baranwal (GAIN) and Justin Coleman (INL)

It is important to have courage and take risks. GAIN is about doing things differently. Innovation and acceleration are vital. We have heard similar messages on this point from all panels.

From the MIT study, capital costs are in yard, cooling, and installation. The issue is not with the neutrons. What are the ongoing/upcoming $R \& D$ activities?

- EPRI will be doing a R\&D study on the detailed code of accounts. The total cost of building a reactor can be broken down into its component parts (e.g., "wedges" of a pie chart). Even if you reduce a single wedge cost to zero, you might not be making meaningful progress if that wedge is not materially important to the overall success of the project. You have to work on all of the wedges.

GAIN can assist the broad advanced nuclear technology community with R\&D. "It's just a sexy science project" if no one buys it. We must move from concept to concrete.

Improved construction plans are needed and they should proceed more like installation projects than unique, ground-up construction projects.

- To reduce requirements/costs, start looking from a codes and standards perspective, including codes and standards during AP1000 development. Several requirements come out of what goes into codes and standards, e.g. ACI359 concrete issues. Vendors should participate in code committees that define what life is going to be like in the future.

- May 2, 2018 is the codes and standards NRC meeting with DOE, GAIN, and the American Nuclear Society. The topic will be gaps in the current codes and standards.

- Not enough developers are engaged in the standards process. That is the pathway to building anything related to civil engineering or structures. More developers need to be engaged. Socialize committees to the type of work being done and the standards needed.

- Standards need to accommodate new types of structures. Standards must also be integrated, reducing the silos of different organizations. Disciplines must talk with one another to streamline development of new reactors.

- DOE/labs might be good facilitators for standards integration.

- Designers tend to think through the ASME prism. Structures are usually EPC responsibility (Fluor/Bechtel's responsibility, not Westinghouse/GE). The vendor stands to reap major benefits by understanding structures. "Do not make it an afterthought. It is an integral part of the facility."

- In general, all entities should get involved in the standards process. Sending young scientists and engineers to these meetings is a great opportunity for professional development. This is a great way to set your own path if you do not like the current regulatory process. Another group that is not involved enough is utilities/end users.

- Not all these standards were in place during the historical construction period for advanced reactors. Sometimes codes and standards are more of a restriction than an aid. Developers need to get involved or they will risk impacts down the line.

- As a developer, when R\&D priorities are set, we do think about structural components. 
- So many different societies hold different standards. We need a better understanding of how NRC handles integrating different societies and codes. If we have an R\&D question, whom do we ask? $\mathrm{NRC}$ as an integrator? At the end of the day, NRC has to approve/license it.

- It would be very helpful to better understand the process, especially during R\&D prioritization/resource allocation.

\section{The need for HALEU is at the top of many developers' lists}

- GAIN and NEI are working on a path forward. Developers need to communicate requirements.

- Fuel qualification facilities (e.g., versatile neutron source) are needed. GAIN can help.

- How do developers find spent fuel and plutonium? Not everybody needs it.

- Regarding HALEU, do not lose track of other supply chain issues by only focusing on this one high-profile issue. For example, the molten salt community needs high-quality salt, Li-6, etc. This is an opportunity for the U.S. to cultivate a solid supply chain.

- A broader/more diverse portfolio creates better outcomes. More idea diversity will result in better outcomes overall. However, the total pool of money invested must at least be competitive with foreign powers.

Referring to SRP comments from Day 1, local utilities are making plans for the future, but nuclear is not a part because they do not know what to do with it. How do we work with municipal/smaller power providers to educate, help, and facilitate them?

- GAIN can make introductions. The lab system has experience and connections. Success also relies on end users and developers to step in to educate the SRPs of the world. As mentioned earlier, the utilities need help understanding how nuclear fits into their strategy.

- A product is needed that can be operated in a cost-effective manner. Who has a product that can appeal now to someone making portfolio-planning decisions? Where is the customer? Southern is great, they take the long view, but it is a long view process because we do not currently have an immediately viable product.

- If I am a municipal power provider and I want to sell electricity, where do I hire people to operate and sell electricity?

- Is there information from the Conference of State Legislators? Are they the right group to help facilitate this outreach?

- Currently, utilities do have entities like Google and Amazon explicitly demanding renewables. We need to figure out how to get communities and other users to demand this product.

\section{What is the Siting Process for demonstration reactors?}

- Our recommendation should not just be "contact so and so." There should be a 2-3 page fact sheet about what it takes to get it done. For example, what is the menu/roadmap of things to accomplish? Not everything can be laid out in infinite detail, but in broad terms, what does it take? Canada has a variety of similar helpful material. 
- A reactor park hearkens back to the Canadian idea. Having a development park where you can site and test your FOAK unit can be done through government funds, so that developers do not have to solely carry that burden. This can be done now. It does not require progress on design maturity.

- Design maturity is needed before construction starts. Utilities do not want to buy first/second/third-of-a-kind. What do you do?

\section{What are your thoughts on NASA's milestone-based approach for FOAK?}

- The Breakthrough Institute has a report on this process (https://thebreakthrough.org/index.php/issues/nuclear/commercial-spaceflight).

- NASA transitioned from solely government-driven industry to incentivizing private companies.

- This is beyond just cooperating on R\&D. If you meet technical milestone X, we will pay you \$Y.

- Award prizes (payment) for performance, such as launching/relaunching the same vehicle ' $\mathrm{x}$ ' times in ' $y$ ' period.

- Past performance is not a guarantee of future success.

- There is a rich history-in the Power Reactor Demonstration Program. There were a large number of non-LWRs and different LWR designs being actively explored under this demonstration program.

- The Power Reactor Demonstration Program is a "Jewel of examples." It was enormously successful.

- These were built and operated by government-industry consortia. The Atomic Energy Commission worked with industry to actively promote60+ industries to put together proposals for FOAK For example, Fermi 1 was $90 \%$ funded by industry.

- However, cost-shares with rigidly defined terms do not work for such unique and complicated technology. Government versus private share needs to reflect technology maturity and partners coming to the table. For example, government dominated Elk River deployment. The host utilities were smaller and rural.

- All different types of utilities were engaged by this program, from large vertically integrated utilities to co-ops and municipal power providers. Some interesting designs were built and operated (e.g., reactor in Piqua, Ohio).

- NASA has a range of techniques and incentives they have used for technologies from basic research through demonstration, providing a solid foundation (e.g., SpaceX). Market timing and time-to-maturity are comparable with nuclear for some of these NASA-incentivized projects.

- GAIN should reach back into the NASA object lesson to see how they did it. Look at the specific techniques. How did the Atomic Energy Commission get individual utilities, industrial partners, and vendors together to make those selections? What was the process? This would be helpful information for today. We need to see some of these examples of how we could proceed.

\section{Additional participant discussion:}

- We are trying to build a bridge. The developer is building from this side, utilities supposedly coming from the other side, but we are not seeing genuine utility movement. How do you get the bridge across? Who is missing from the process? Where is private capital? Why are they not at this type of meeting? 
- The MIT study is interesting but the near-suggestion that nuclear only has a future if we value carbon is bothersome. The UK put a value on carbon and that changed the UK government's mind about wanting to do nuclear. As a community, we also need to underline other positives.

- Before we get too deep into the conversation about competition and down selection among designs, we first must win the conversation more generally that nuclear is the way forward. Focus on the core conversation over the specific type of nuclear to implement. Nuclear is carbon free, energy security, and resilient. Need to emphasize why nuclear is resilient.

- You have to pay more for nuclear and its resilience. Strength of buildings, safety standards, etc., come at a real economic cost that has to be explicitly valued. It is vital to convey that message to the community at large.

- Whom does the message need to go to? Not the utilities, not the customers.

- The only thing that will get you in the door is competing on cost. Cost is the only thing that a utility executive is being evaluated on

- Whether the utility is regulated or deregulated, there is no monetary value to non-economic factors. "Without economic value, there is no decision."

- This community has spent a lot of time talking to each other about how great nuclear is, but we're beyond that. The practical issue is a race to the bottom on price in the power markets.

- Messages need to be in policy space, relayed to both federal and state legislators. This issue is "not customer related," they are not making the decision. If companies are ordered to build nuclear and charge $10 \%$ more for resiliency or other benefits, they will not resist, but they will not take those initiatives on their own.

- "Nuclear patriotism" is pointless.

- We need to be talking to state legislators and the federal government. There is just not enough of us yet. We need to grow the movement, but it is not easy. We have heard it from a few different people, but there are many of the same people at every event.

- We need to be more strategic and intentional about reaching into other circles (such as clean technology groups and forums) that never talk about nuclear and have their own insularity problems. It is important to reach out to different environmental groups in a purposeful way. However, it will not happen overnight.

- Policy changes are needed to make the value proposition of nuclear clear and rewarded. To build a nuclear plant, you need an NRC license, which costs more than even a demonstration plant. Federal policy needs to change.

- Resilience also means flexibility of technology. There is value in various types of electrons and hybrid systems. It would be good to get more $R \& D$ into additional benefits of nuclear systems. It can be a big niche to build up that type of infrastructure. Integration is needed into the other end products and end users. 


\section{Appendix D, Gallery Walk Posters and Discussions}




\section{California}

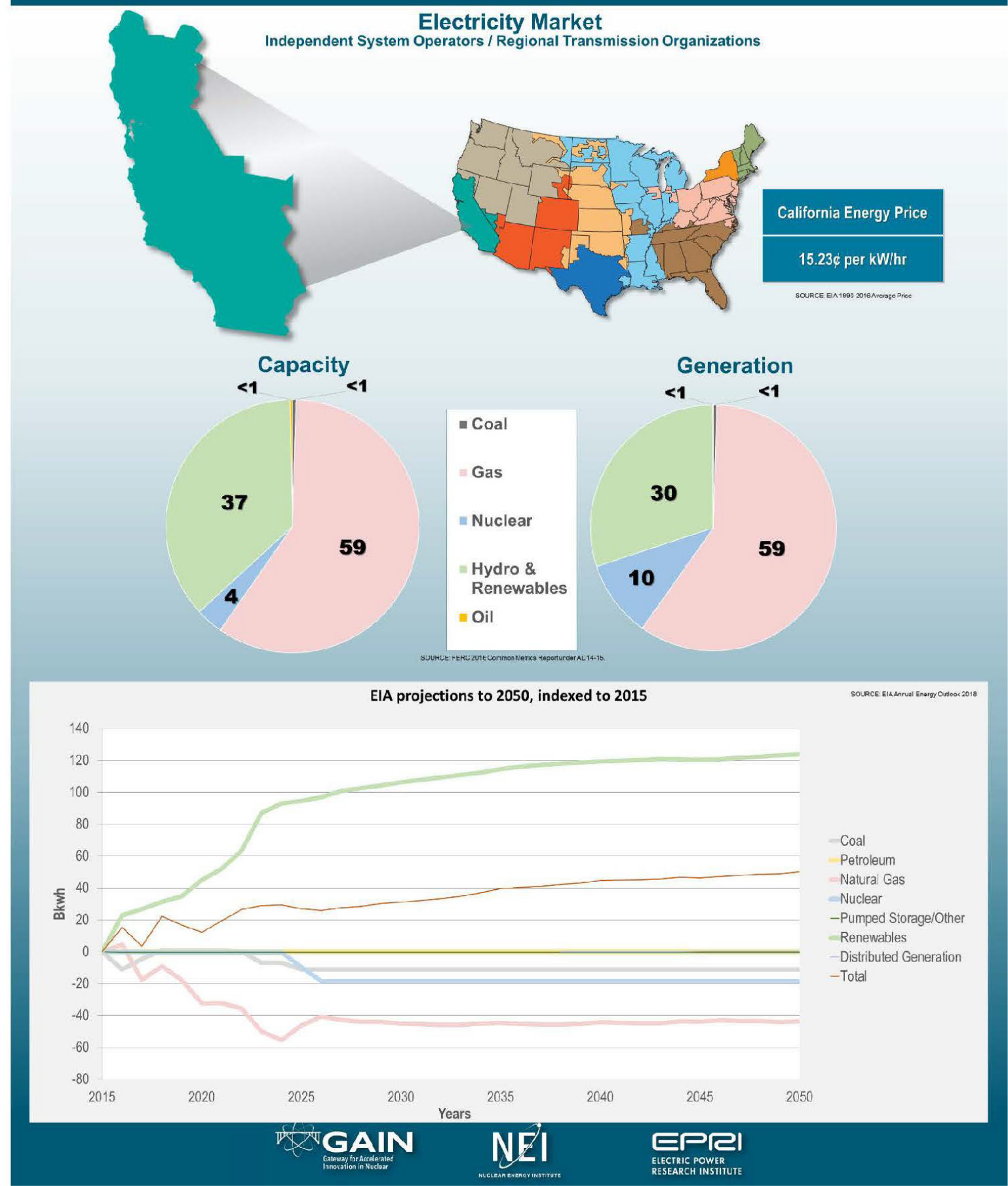

Electricity Market 


\section{California}

\section{Opportunities}

- Industrial (desalination?) use (long range)

- Climate change attitudes/leadership (willingness to pay for green energy)

- Increased demand, vehicle electrification

- Economic base for the community

- Baseload diversification

- High electricity prices
Barriers

- Political

- Social/perception

- Transmission limitations

- Regulatory

- Familial vendetta

- Water rights

\section{Potential Actions}

- Risk communication and public perception effort (tie to climate impacts)

- Universities to drive change 


\section{Midcontinent}

Electricity Market

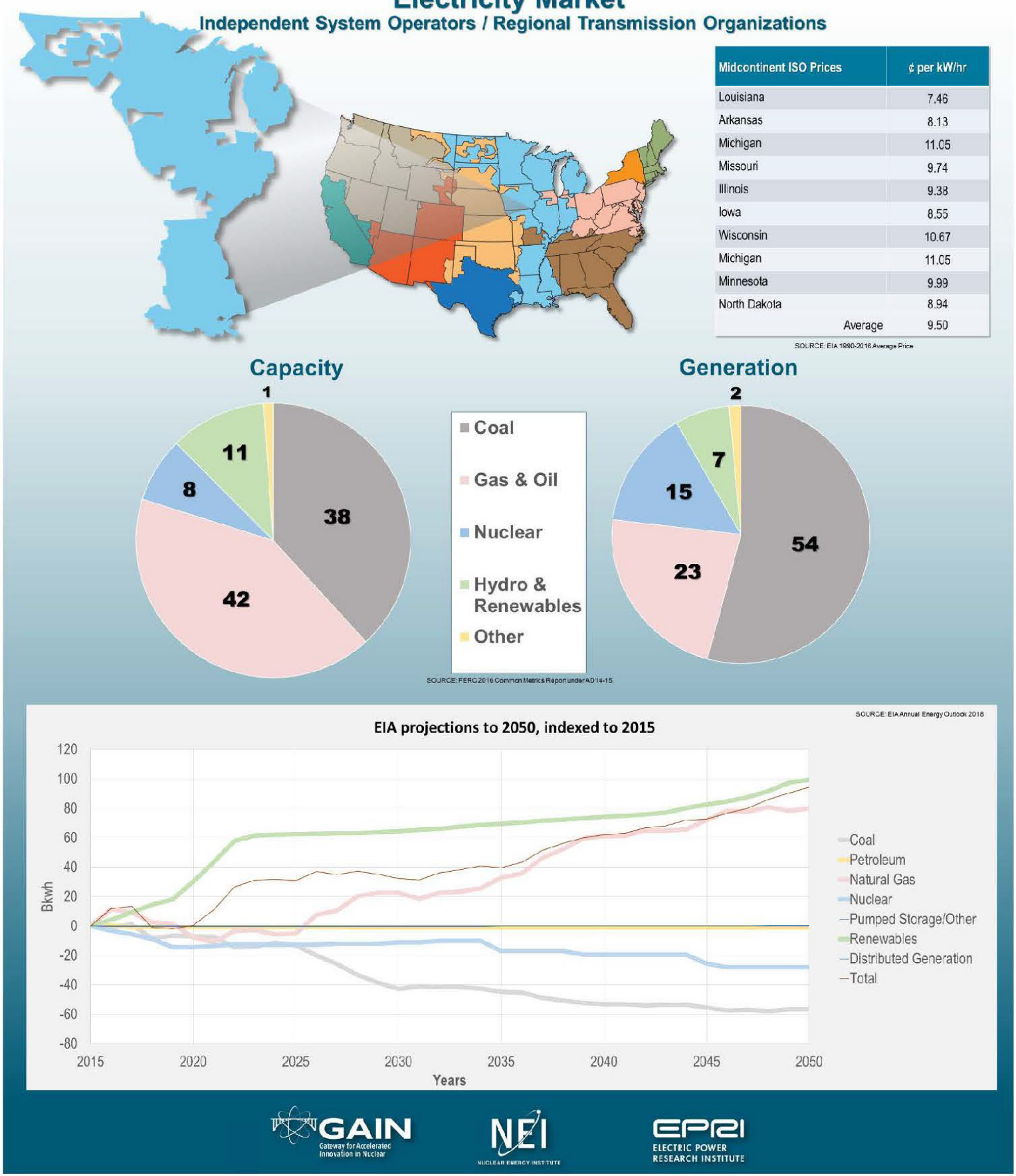




\section{Midcontinent}

\section{Opportunities}

- Expiration of production tax credits for renewables (if not renewed)

- Replace capacity loss due to plant retirements

- Reliance on coal hurts consumers (Clean Power Plan, air quality)

- Areas densely populated, no wind

- Transmission congestion

- Siting in arid locations
Barriers

- Some ban nuclear build

- Abundance of wind

- Natural gas price 20 years out

- Advancement of storage

- Resiliency valued differently (cold north, hurricanes in the south)

- Transmission congestion

\section{Potential Actions}

- Use universities and nuclear plants' visitor centers to drive conversation

- Advocate with state legislatures

- Recognize resiliency

- Carbon value by state legislature 


\section{New England}

Electricity Market

Independent System Operators / Regional Transmission Organizations

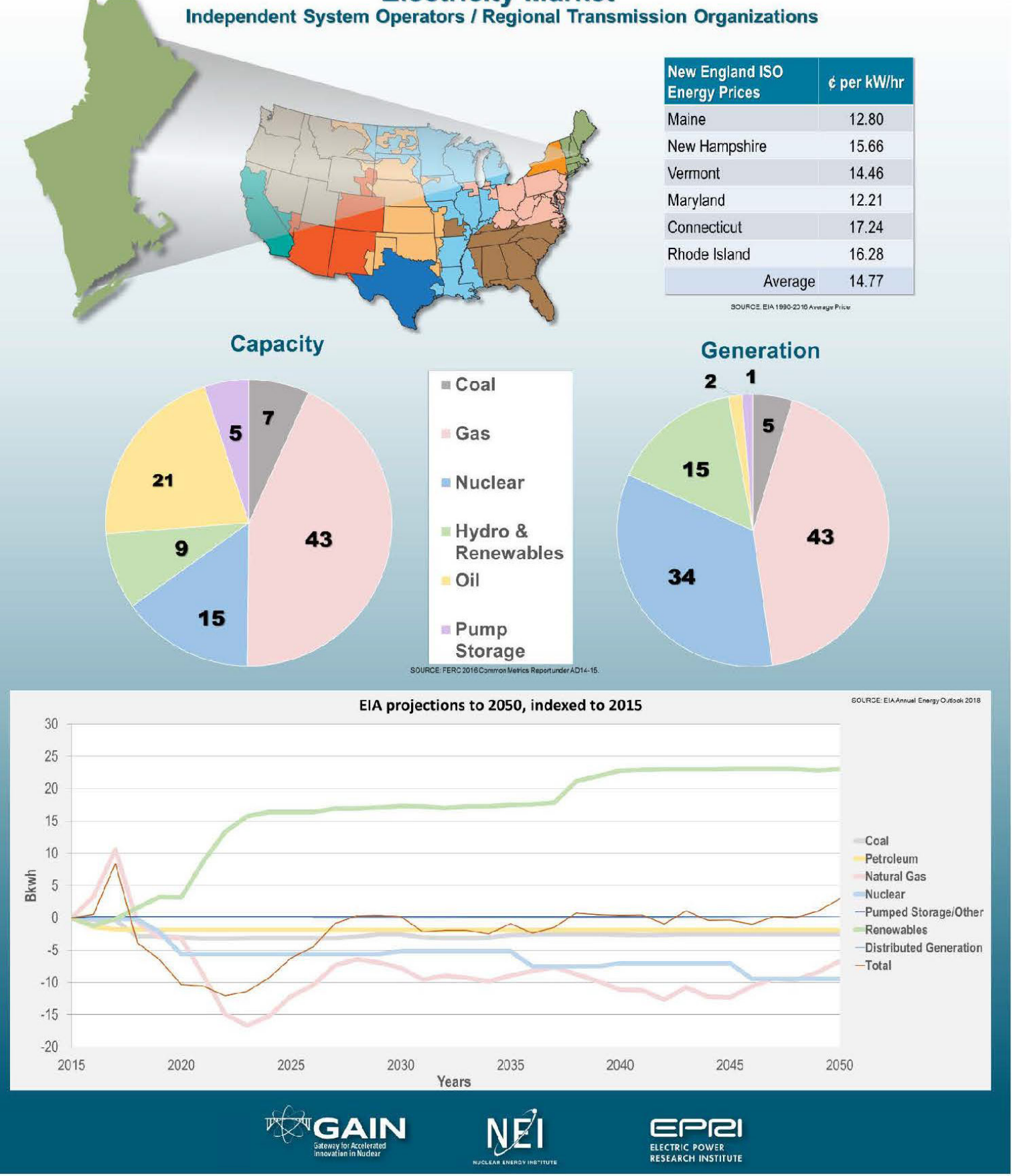




\section{New England and New York}

\section{Opportunities}

- Weather-independent reliable generation

- Carbon free

- NEISO report on resiliency and vulnerability

- High retail prices relative to rest of country (price competition less stiff)

- Replace home heating oil

- Strong opposition to expanding natural gas transmission/distribution networks

- Clean energy standard

- New generation needed to replace retiring nukes

- Lack of gas pipelines

- Canadian plants

- New York City blackout fear

\section{Barriers}

- Anti-nuclear sentiment

- Energy market is flat over next $\sim 30$ years

- Canadian imports

- New York City distributed energy requirement (REM)

- Battery storage--momentum, cost trend, FERC order

- Lack of transmission lines

- Heat storage (thermal heat)

- Politically-forced retirements of Pilgrim and Indian Point

- Natural gas influence

- Offshore wind investments

- New York City blocking the Northeastern U.S. pipelines

\section{Potential Actions}

- Expand Zero-Emission Credit program through the Regional Greenhouse Gas Initiative

- Study on effects of nuclear retirements (carbon, costs)

- Value for capacity (fuel on site)

- Market value of service continuity/rapid restoration after severe weather events

- Take away renewable subsidies

- Stricter rules (environmental) on fracking 


\section{New York}

\section{Electricity Market}

Independent System Operators / Regional Transmission Organizations
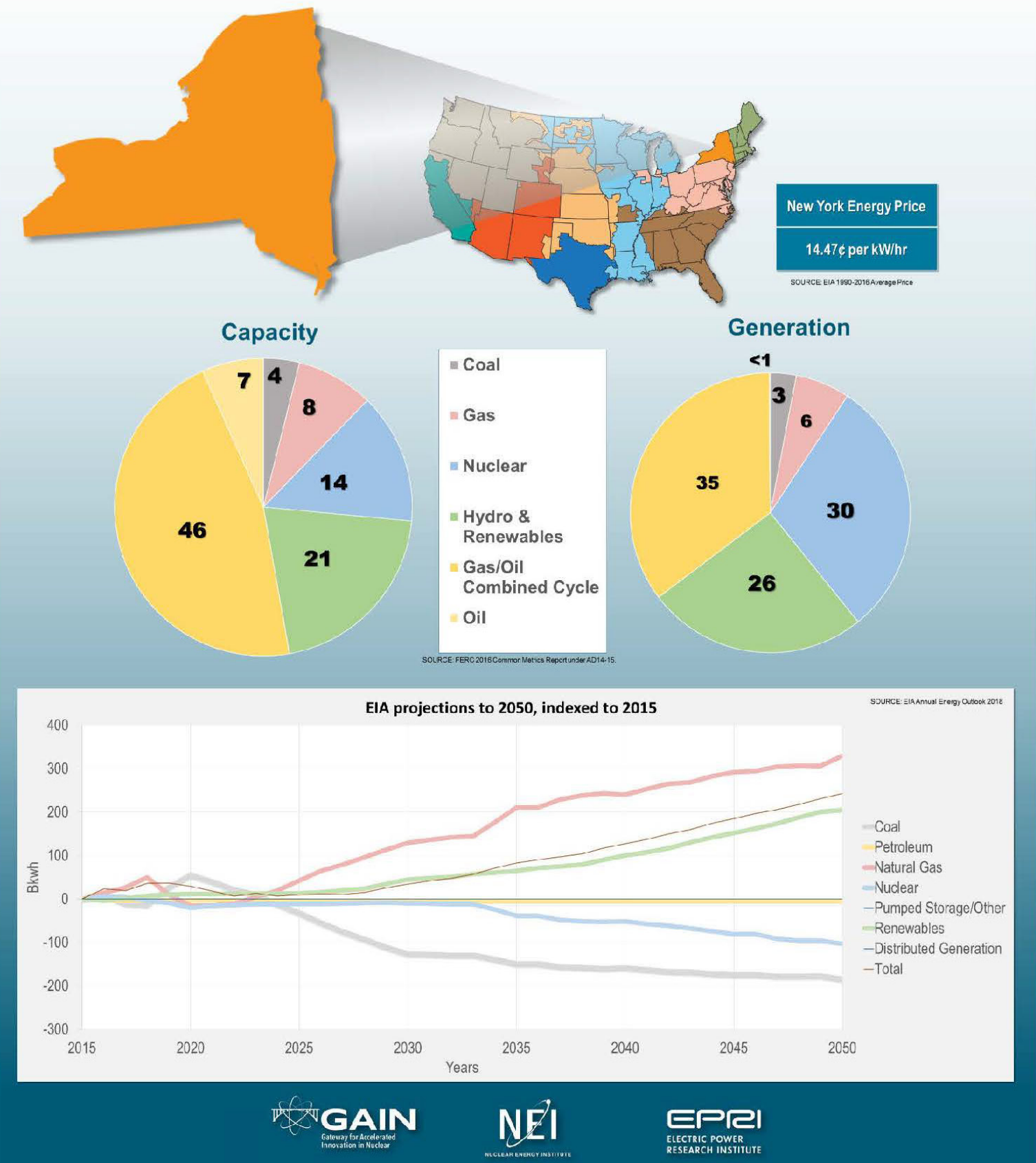


\section{New England and New York (duplicated)}

\section{Opportunities}

- Weather-independent reliable generation

- Carbon free

- NEISO report on resiliency and vulnerability

- High retail prices relative to rest of country (price competition less stiff)

- Replace home heating oil

- Strong opposition to expanding natural gas transmission/distribution networks

- Clean energy standard

- New generation needed to replace retiring nukes

- Lack of gas pipelines

- Canadian plants

- New York City blackout fear

\section{Barriers}

- Anti-nuclear sentiment

- Energy market is flat over next $\sim 30$ years

- Canadian imports

- New York City distributed energy requirement (REM)

- Battery storage--momentum, cost trend, FERC order

- Lack of transmission lines

- Heat storage (thermal heat)

- Politically-forced retirements of Pilgrim and Indian Point

- Natural gas influence

- Offshore wind investments

- New York City blocking the Northeastern U.S. pipelines

\section{Potential Actions}

- Expand Zero-Emission Credit program through the Regional Greenhouse Gas Initiative

- Study on effects of nuclear retirements (carbon, costs)

- Value for capacity (fuel on site)

- Market value of service continuity/rapid restoration after severe weather events

- Take away renewable subsidies

- Stricter rules (environmental) on fracking 


\section{Northwest}

Electricity Market

Independent System Operators / Regional Transmission Organizations

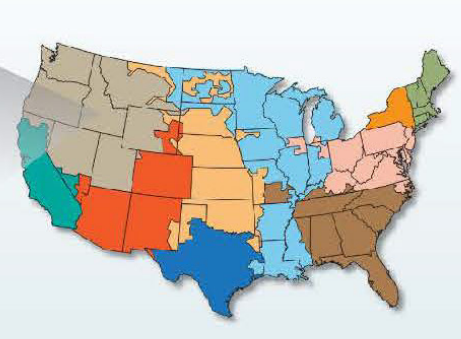

Generation

$<1$
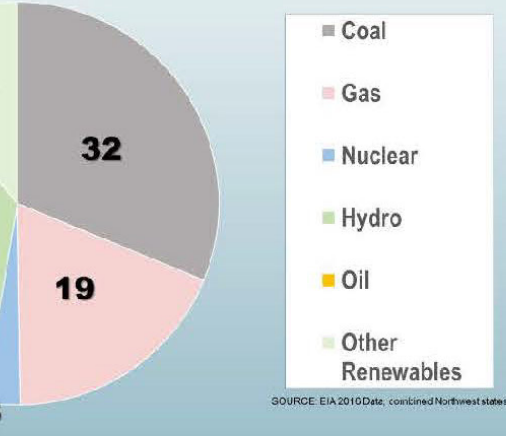

EIA projections to 2050, indexed to 2015

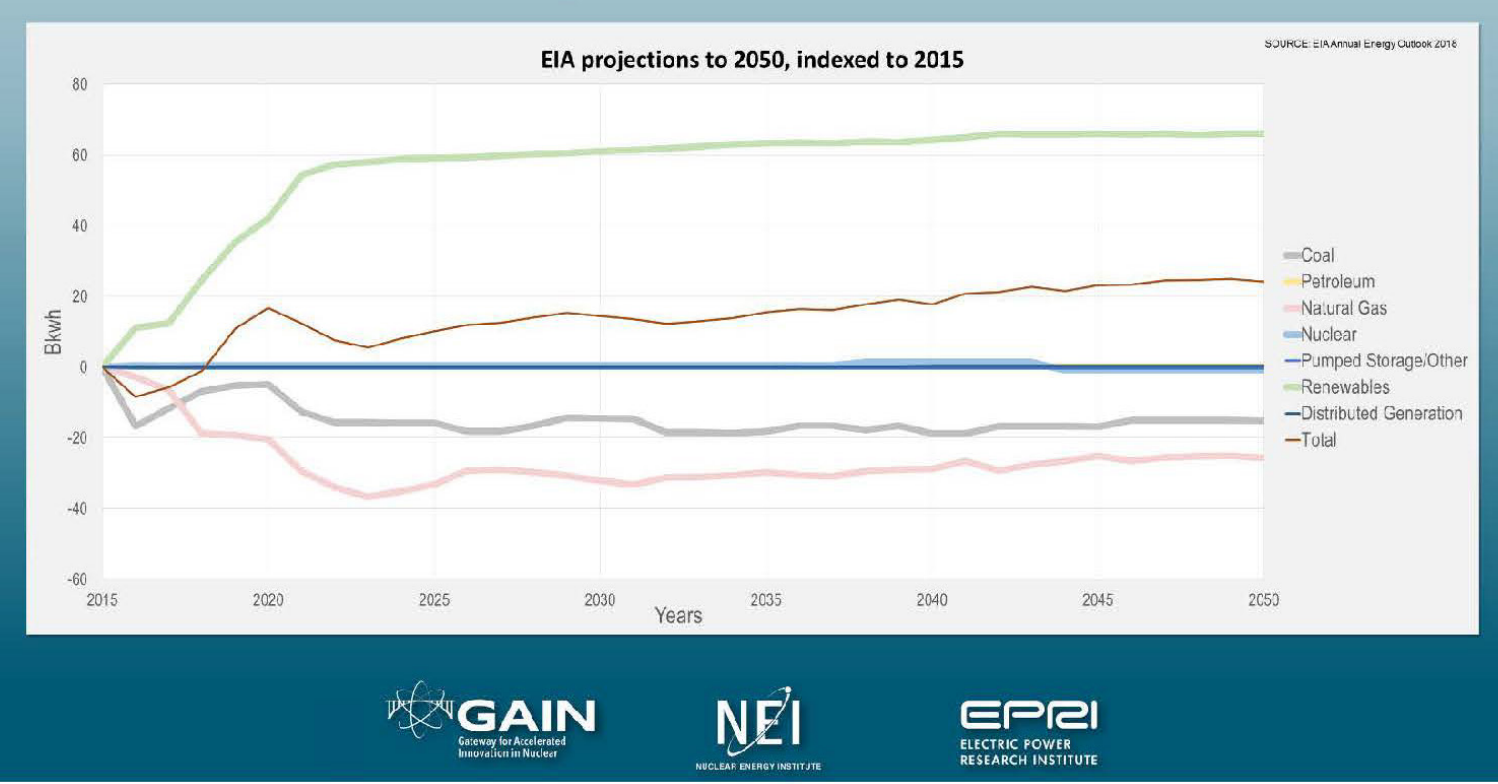

\begin{tabular}{|c|c|}
\hline Northwest Energy Price & \& per kW/hr \\
\hline Washington & 7.68 \\
\hline Oregon & 8.83 \\
\hline Nevada & 8.39 \\
\hline Montana & 8.84 \\
\hline Idaho & 8.05 \\
\hline Wyoming & 8.19 \\
\hline Utah & 8.72 \\
\hline Average & 8.38 \\
\hline
\end{tabular}

SOURCE: EIS 1950-2010 Average

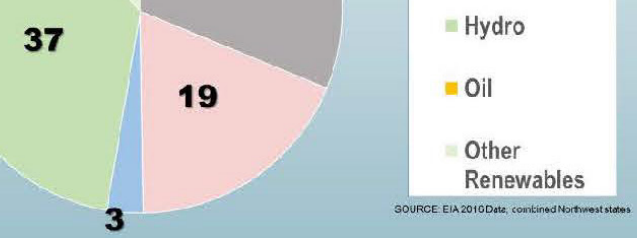




\section{Northwest}

\section{Opportunities}

- States with RPS need to expand definition of "qualifying renewable"

- Replacement of coal-fired power plants

- Population growth? (significant percentage, small numbers)

- Export to California with population growth there (and loss of generation)

- Low population density (siting options)

- Using nuclear to balance increase in wind or to support severe weather events

- Capacity growth (vitrification plant dedicated support from an SMR?)

- SMR could leverage regional expertise, infrastructure of Energy Northwest

- Replacement of Hanford Mission jobs and resources when mission is complete

- Fast Flux Test Facility restart?
Barriers

- RPS does not include nuclear

- Energy export and influence of policies outside region (California)

- Economic competitiveness (hydro, coal)

- Cross-state transmission

- Educating region on value of nuclear

- Reluctance to accept nuclear in parts of region (e.g., Seattle, Portland)

- Demand/market for new generation?

- Geology (mountainous)

- Pumped hydro impact on other water use

- Plant siting

- Bad legacy of Hanford

\section{Potential Actions}

- RPS modification

- Synergies with nuclear, fossil, hydro, wind, feedstock, transportation fuels

- Review impact of potential dam closures

- Carbon trading

- Clarify potential resiliency impact under severe weather events (winter peaking region--no hydro, too cold for wind, etc.)

- Assess potential to use infrastructure from retiring coal plants 


\section{PJM Interconnection}

Electricity Market

Independent System Operators / Regional Transmission Organizations

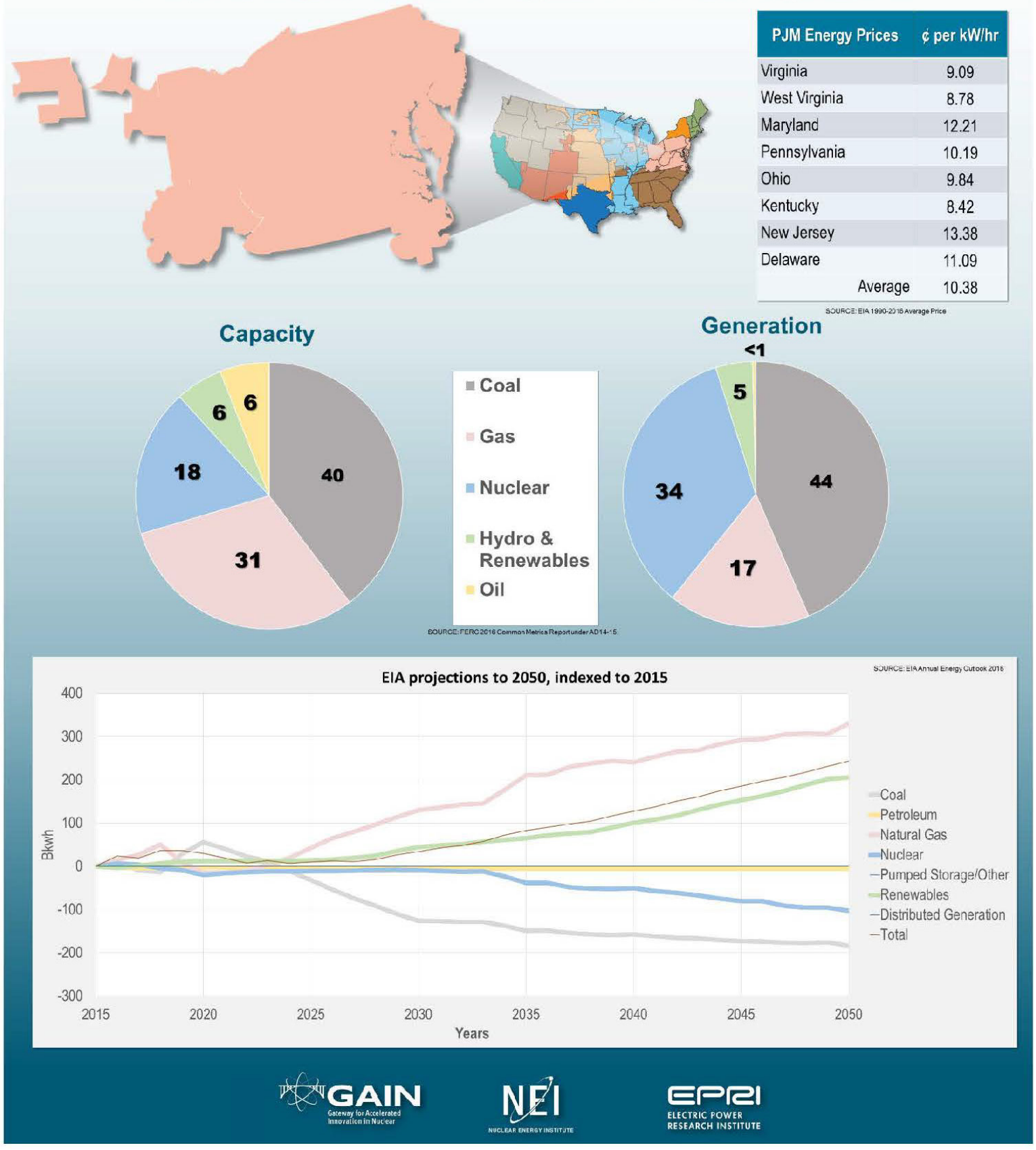




\section{PJM Interconnection}

\section{Opportunities}

- Ability for large coal replacements

- Regional Greenhouse Gas Initiative

- Already a well-established nuclear market

- Water sources in large availability

- University pipelines

- $25 \%$ tariff on steel (Pittsburg, Pennsylvania)

- Work force knowledgeable

- Sustaining the large LWR fleet
Barriers

- Renewable mandates increase legislative costs for nuclear

- Regulated energy markets (in some areas)

- Price formation

- Natural gas is abundant; however, pipelines are challenged in terms of regulation--further depression of price

- PJM institutional inertia

- Stalled state legislation in New Jersey, Pennsylvania, Ohio

- Public opposition

- Long-term funding support in unregulated market

\section{Potential Actions}

- Regional market reform valuing nuclear and repurpose PJM

- Federal legislation

- Emergency very SMR capabilities in response to storms

- Need for dispersed power in Pennsylvania, West Virginia, and Virginia

- Educating state regulators/customers 


\section{Southeast}

\section{Electricity Market}

Independent System Operators / Regional Transmission Organizations

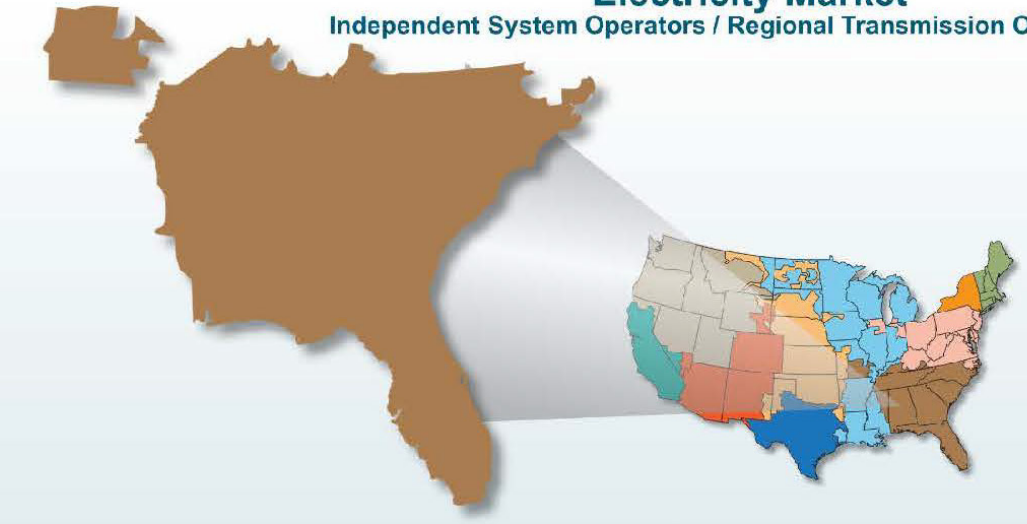

\begin{tabular}{lcc} 
Southeast Energy Prices & per kW/hr \\
\hline Florida & 9.91 \\
Georgia & 9.59 \\
Alabama & 9.56 \\
Tennessee & 9.23 \\
South Carolina & 9.79 \\
North Carolina & 9.20 \\
& Average & 9.55 \\
\hline
\end{tabular}

4

\section{Generation}

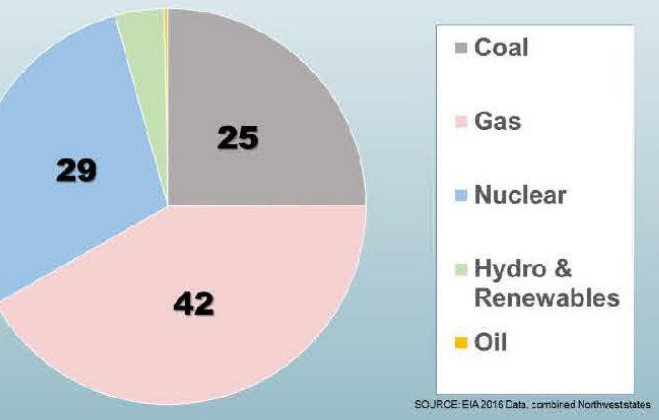

EIA projections to 2050, indexed to 2015

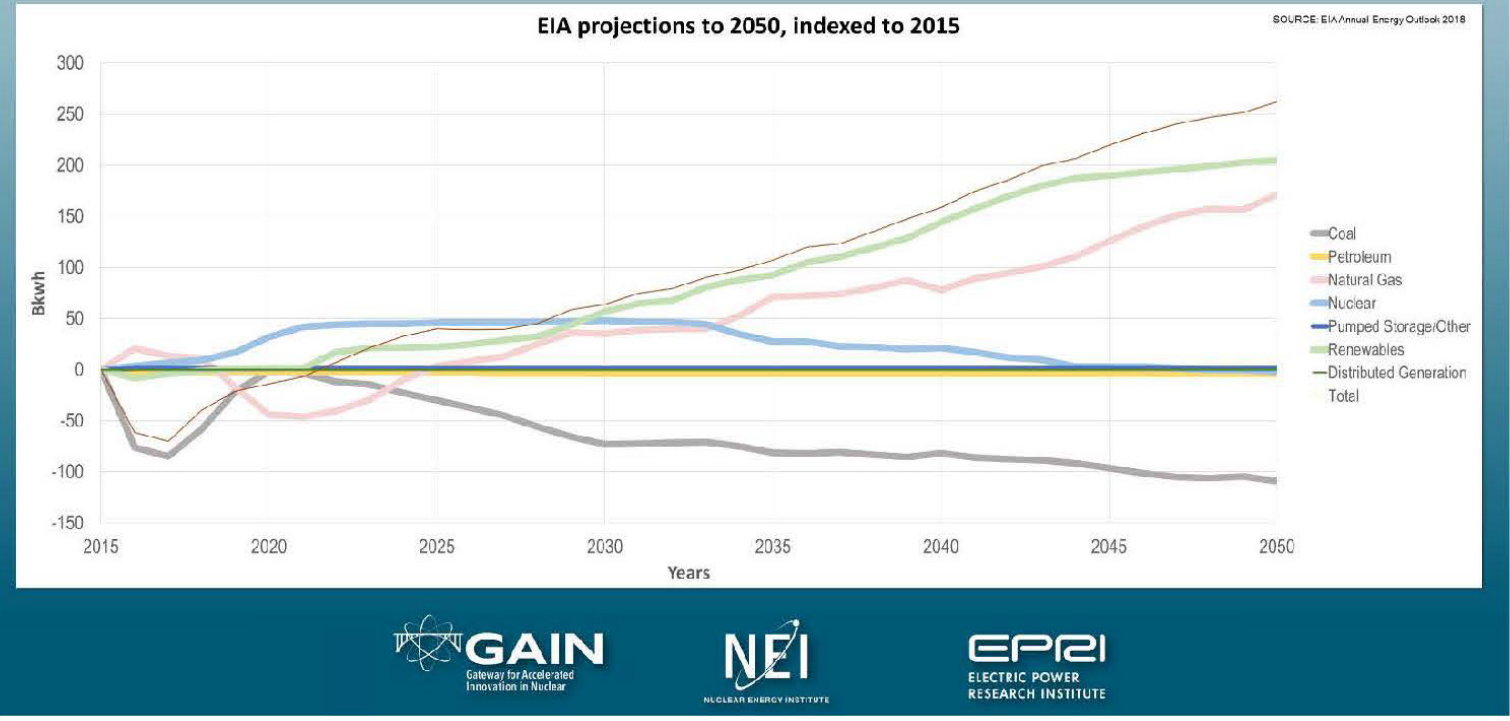




\section{Southeast}

\section{Opportunities}

- Ability to make long-term resource planning decisions

- Strong national lab presence

- Influence of state level policy changes (and opportunity)

- Military and federal reservations

- Lots of cars, population density--load growth from electric vehicle adoption

- $9 \mathrm{c} / \mathrm{kWh}$ works

- Pu stockpile

- Spent fuel processing capability and experience

- Licensed sites not being utilized

- Fossil plant retirements

- Established nuclear market with dense pockets of established groups
Barriers

- No benefit to utility to do a risky project

- Economics (lower $\$ / \mathrm{kW}$ and operation and maintenance)

- Workforce concerns

- Project management abilities to construct plant on-schedule and on-budget

- Need for flexible generation (ramp > $10 \mathrm{MW} / \mathrm{min})(20-100 \%$ output range); accommodate renewables in flux

\section{Potential Actions}

- Federal legislation on long-term energy policy

- State or regional energy diversity requirements 


\section{Southwest Power}

Electricity Market

Independent System Operators / Regional Transmission Organizations

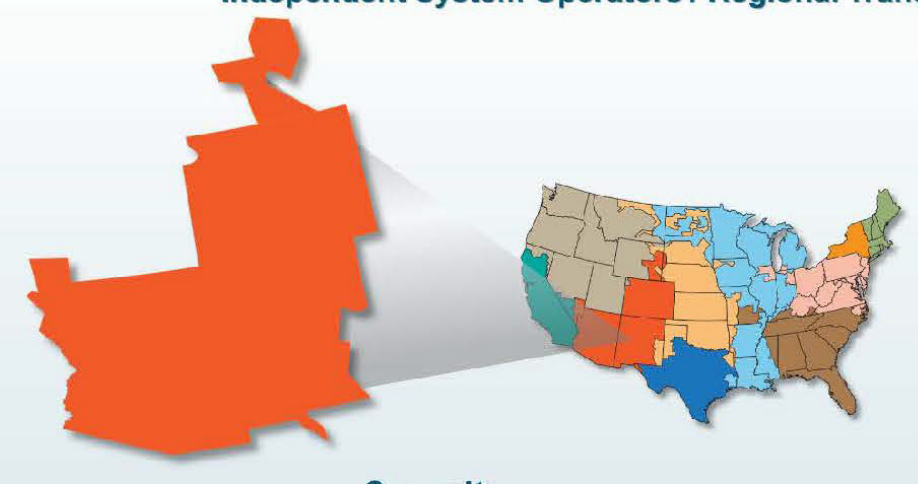

Southwest Power Pool

Energy Prices

\& per kW/hr

Arizona

Colorado 10.33

New Mexico 9.83

1 Capacity

Generation

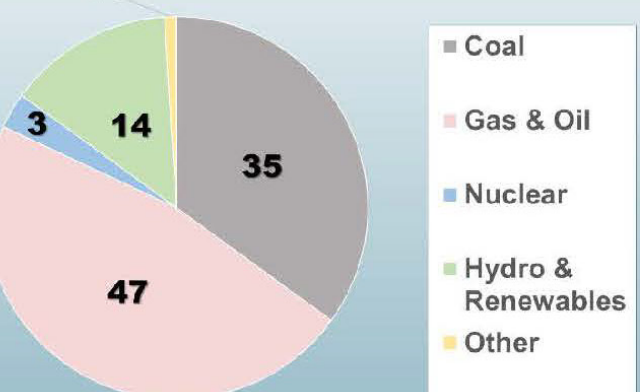

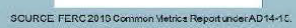

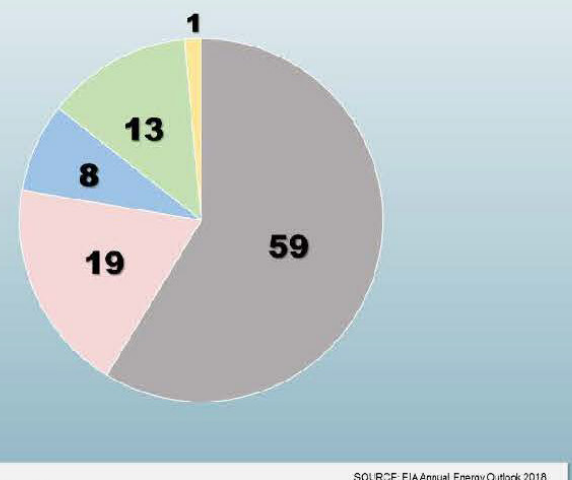

EIA projections to 2050, indexed to 2015

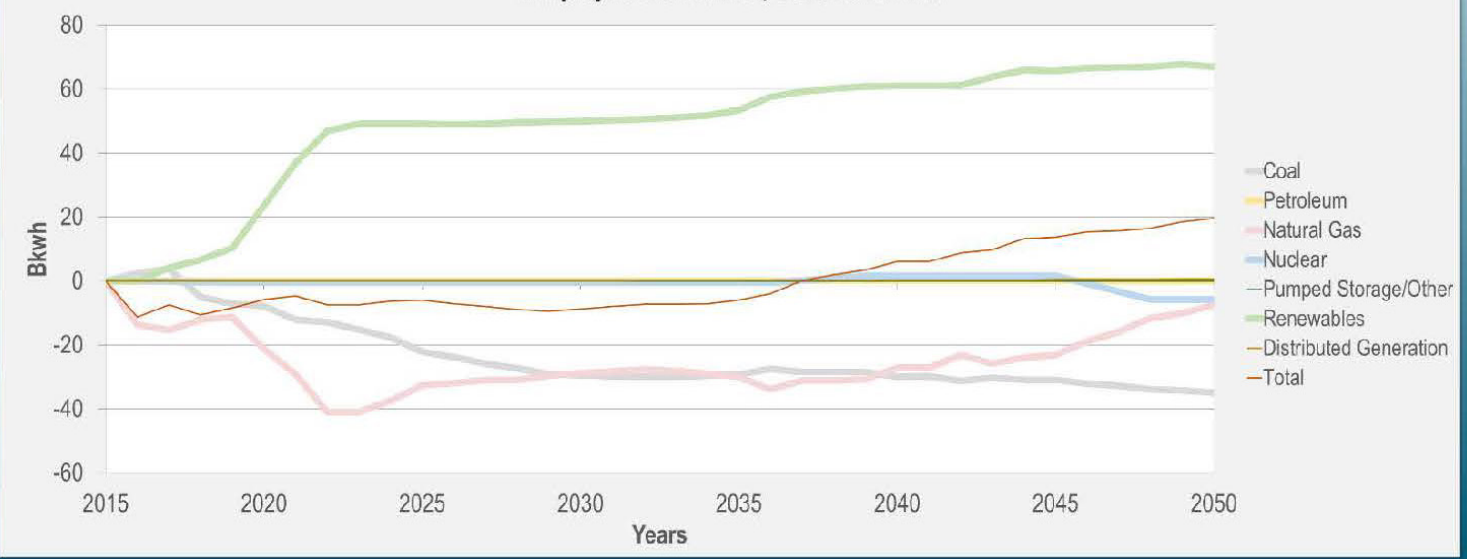




\section{Southwest Power}

\section{Opportunities}

- Desalination (but see barriers)

- Microgrids alleviate geographic challenges

- Replacing retiring fossil generation

- Advanced reactors that do not need water cooling

- Carbon free backup generation
Barriers

- Flat demand

- Water rights in the Southwest

- Surface water $100 \%$ allocated

- Groundwater and recharge

- Public land

- Low commercial nuclear power exposure

- Negative perception with defense activities

- Renewable competition

\section{Potential Actions}

- Tailor hybrid renewable-nuclear systems to the region

- Proactive public outreach

- No water use for cooling

- Design to complement renewables 


\section{Energy Reliability Council of Texas}

Electricity Market

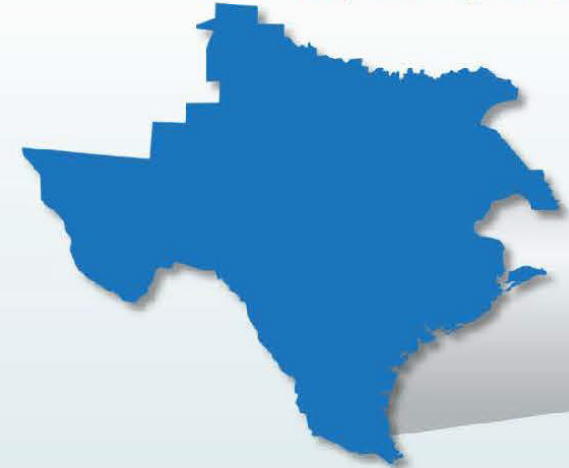

Capacity

1

20

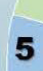

5

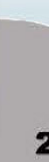

21

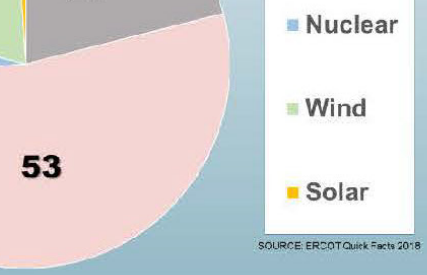

EIA projections to 2050, indexed to 2015

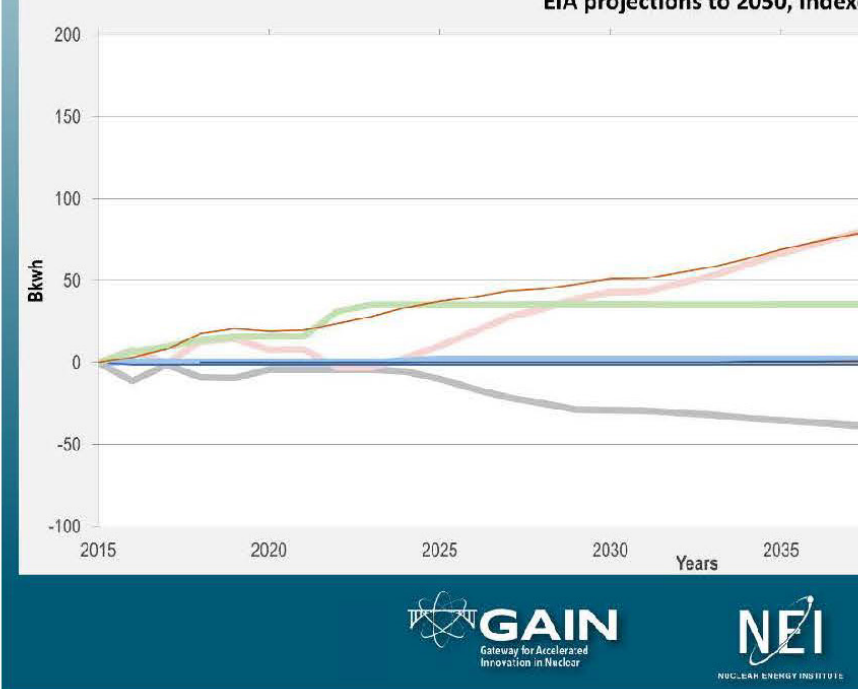

SOUROE EIAARnual Enorgy OAtlock 2010
Texas Energy Price

8.43\% per kW/hr

SOLRCE: EIA 1990.2C10A Average Pice

Generation

17

11

32

39

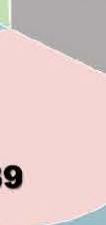




\section{Texas}

\section{Opportunities}

- Multiple existing nuclear sites owned by separate utilities

- Diversity of opinions and decision making

- Ready-to-deploy site (STP)

- Coal retirements

- Industrial markets (refineries/chemical plants)

- Relative load growth

- Flexible deployment/renewable integration potential

- Federal climate policy may make renewables with high $\mathrm{CO}_{2}$. Nuclear can help with backup

- Dispersed load

- Large nuclear plants near cities

- SMR/very SMR to reduce distribution

- Large state

\section{Potential Actions}

- Talk to oil/chemistry companies

- Federal legislation

- Eliminate biased RPS/renewable mandates

- Net metering

- Maintain existing fleet
Barriers

- Low natural gas price

- Natural gas has strong political/employment influence

- Wind/renewable penetration 


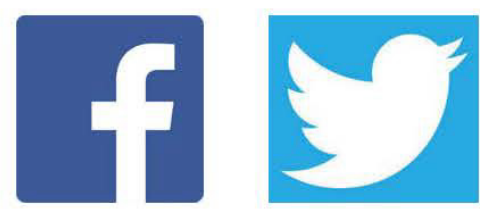

@GAINnuclear | gain.inl.gov 